\title{
GCU
}

Glasgow Caledonian

University

University for the Common Good

\section{Is the evolution of building sustainability assessment methods promoting the desired sharing of knowledge amongst project stakeholders?}

Thomson, Craig S.; El-Haram, Mohamed A.

Published in:

Construction Management and Economics

DOI:

$10.1080 / 01446193.2018 .1537502$

Publication date:

2019

Document Version

Author accepted manuscript

Link to publication in ResearchOnline

Citation for published version (Harvard):

Thomson, CS \& El-Haram, MA 2019, 'Is the evolution of building sustainability assessment methods promoting the desired sharing of knowledge amongst project stakeholders?', Construction Management and Economics, vol. 37, no. 8, pp. 433-460. https://doi.org/10.1080/01446193.2018.1537502

\section{General rights}

Copyright and moral rights for the publications made accessible in the public portal are retained by the authors and/or other copyright owners and it is a condition of accessing publications that users recognise and abide by the legal requirements associated with these rights.

Take down policy

If you believe that this document breaches copyright please view our takedown policy at https://edshare.gcu.ac.uk/id/eprint/5179 for details of how to contact us. 


\section{Is the evolution of building sustainability assessment methods promoting the desired sharing of knowledge amongst project stakeholders?}

Craig S Thomson ${ }^{\mathrm{a} *}$ and Mohamed A El-Haram ${ }^{\mathrm{b}}$

${ }^{a}$ Department of Civil Engineering and Environmental Management, Glasgow Caledonian University, Glasgow, UK;

${ }^{b}$ Whole Life Consultants Limited and Division of Civil Engineering, University of Dundee, Dundee, UK.

${ }^{a}$ Dr Craig Thomson (Corresponding author)

Dr Craig Thomson, Senior Lecturer in Sustainability and the Built Environment, Department of Civil Engineering and Environmental Management, School of Computing, Engineering and Built Environment, Glasgow Caledonian University, Glasgow, UK.

craig.thomson@gcu.ac.uk

${ }^{\mathrm{b}}$ Dr Mohamed El-Haram

Dr Mohamed El-Haram, Managing Director of Whole Life Consultants Limited and a Senior Research Fellow in the Construction Management Research Unit, Division of Civil Engineering, University of Dundee, Dundee, UK.

Body text: 13600

Abstract: 188

Appendix 3

Tables 4

Figure 7 


\title{
Is the evolution of building sustainability assessment methods promoting the desired sharing of knowledge amongst project stakeholders?
}

\begin{abstract}
Building sustainability assessment methods (BSAM's) seek to help project stakeholders understand the predicted and actual sustainability performance of their buildings but are often applied reactively and isolated from project decisions. The last decade has seen BREEAM at the forefront of evolving assessment practice towards a framework approach to help shape project decisions and promote stakeholder learning. The research explores the nature and extent this transition is being realised in practice within four case studies applying BREEAM spanning a fifteen-year period. Process and knowledge mapping techniques are applied to explore the flow of knowledge required to enable sustainable decisions, stimulate the sharing of understanding, mediation of views and to promote learning amongst stakeholders. Evidence suggested that when applied in progressive projects that the flow of knowledge is strongest when supported by sustainability leadership, a framework approach aligned with project management, an improvement and engagement culture and a strategy for promoting knowledge flow. As practice matures care is needed to ensure engagement remains high and stakeholders are not isolated from the flow of knowledge as projects increasingly rely on sustainability advisors thus losing the opportunity to learn and shape decisions.
\end{abstract}

Keywords: sustainability assessment, knowledge management, project management, sustainability leadership

\section{Introduction}

The rise of 'Sustainable Construction' has sparked a realisation that the current processes and practices deployed in the development of the built environment are not 'fit for purpose’ (Rees 2009). In the UK, the Strategy for Sustainable Construction (2008), the Low Carbon Transition Plan (2009) and Construction 2025 Industrial Strategy (2013) have provided direction by prioritising the role of the construction industry as a key enabler in realising national carbon reduction targets and delivering 
wider principles of sustainable development. This places pressure on clients and industry professionals to rethink the way that buildings are planned, designed, built, operated, maintained and ultimately disposed of and their support systems (El-Haram et al. 2007). Stiffening building regulations are challenging project teams to deliver the principles of sustainable design and construction within a whole life building perspective, but achieving this remains difficult especially during a period of prolonged economic uncertainty (Hakkinen and Belloni 2011). Despite incremental improvements, a step change is required and will only be achieved when professionals possess a sufficient level of sustainability literacy to support the necessary cultural shift (BIS 2010; Murray and Cotgrave 2007). A number of studies have highlighted that professionals need to understand the implications for their role in order to achieve a quick transition and therefore projects need to become suitable environments to support learning by doing, social and mutual learning (Rodela et al. 2017; Brandon and Lombardi 2011; Munro and Jeffrey 2008; Graham 2000). Enhanced access to project decisions and the surrounding flow of knowledge is widely recognised to benefit stakeholder learning and recognition for the problem, thus sparking an improvement culture and potential for professional upskilling (Pope et al. 2006; Keen et al. 2005). Building sustainability assessment methods (BSAM's) have the potential to support this, however the often reactive and standalone nature of their application has resulted in limited alignment with project decisions and its wider management (Schweber and Haroglu 2014; Lutzkendorf and Lorenz 2011; Boud 2000).

In the last decade, the developers of dominant BSAM's are appreciating these limitations and are slowly evolving the way they are applied in practice towards a framework approach capable of providing guidance to help projects promote best practice. This framework approach has the potential to provide the catalysis for a more 
proactive culture capable of encouraging innovation and fostering understanding, mediation and promoting learning amongst the stakeholders involved. This research suggests that the evolution of BSAM's needs to create opportunities for project stakeholders to access and exchange knowledge at key points providing the basis to facilitate discussion and recognise the potential for change (Cooper 2018; Cole 2012; Ding 2008).

\section{The evolution of building sustainability assessment methods}

Primarily objective based appraisals assessing compliance with nationally recognised best practice; they are used by clients, designers and developers to showcase their sustainability credentials and expertise within their desired markets (Seinre et al. 2014; Walton et al. 2005). Promoted by governments through public procurement and planning regulations, they remain largely voluntary, accrediting complete designs and in recent years have evolved to align with a post occupancy evaluation (POE).

BSAM's have enabled buildings in their respective markets to compare their sustainability performance and have played a key role in the promotion of sustainable design and construction. Each have their own underlying philosophy which provides variation in the coverage of the sustainability issues supported by a credit system weighted to reflect the priorities promoted by the developer. Despite recent moves to broaden the criteria and establish tailored versions for a wider variety of building types, development scenarios and other global markets; they remain short of providing a holistic interpretation of sustainable development around which a progressive approach to delivering a sustainable building can be established (Gibson 2012; Bebbington et al. 2007). Despite this the BSAM developers are continuing to evolve their criteria and are increasingly reflecting on how the methods can evolve to better shape practice by 
contributing to decisions and the evolution of the project as opposed to merely measuring it.

BREEAM (UK), LEED (US), and DGNB (Germany) are the three dominant BSAM’s with global reach and along with HQEtm (France), SB Tool (International), CASBEE (Japan) and GreenStar (Australia) they have encouraged sustainable design and construction through their third party certification schemes for 15 to 25 years and reflect the primary form of sustainability assessment within construction projects (Cole 2005). A recent review by Bernardi et al. (2017) confirmed that the three dominant BSAM's each have their own approach to the coverage of sustainability issues and reflect varying priorities in terms of awarding credits although there are many commonalities.

BREEAM was the first, introduced in 1990 within the UK developed by the Building Research Establishment (BRE) and is closely aligned with national building regulations providing a broader coverage of sustainability issues but with a commercial focus evolving to compliment the planning and regulatory system.

LEED was established in 1998 and learned from BREEAM in terms of its methodological approach democratically working with stakeholders in a transparent way it was tailored to reflect the ecological 'green' priorities of the US Green Building Council (USGBC) as they seek to overcome its limited consideration in the US planning and building system.

DGNB is a newer method and launched in 2009 by German Sustainable Building Council displaying a similar coverage as BREEAM but promotes a more quantitative approach reflecting lifecycle building performance with tougher thresholds around technical standards 
It can be argued that the more commercial BRE are placing a stronger emphasis and evolution around its BSAM's role as a framework for shaping practice and thus provides the primary focus for the research due to its increased focus on supporting project development through accredited BREEAM assessors and where appropriate sustainability advisors with an increasing trend for their involvement as part of the team. As the oldest of the BSAM's it has gone through the longest development cycle, and remains the widest applied globally with 556,600 certified buildings and 2 million registered for assessment since 1990, with LEED only at 89,600 and DGBC at 718 (Bernardi et al. 2017). The degree which BREEAM is aligned with the UK regulatory system is also important as the UK government are keen to work with the BRE to promote best practice and encourage projects to go beyond compliance, with the BRE working to contextualise for other national markets. As the other BSAMs are also considering how to establish a better alignment with shaping practice and have followed BREEAM to varying degrees in their own development, the lessons emerging should provide relevance internationally.

Role of BSAM's in moving beyond compliance

As we seek to deliver a step change in practice some suggest that instead of promoting innovation, BSAM's are in fact reinforcing a culture focused on compliance with regulations and marginal incremental improvements (Rees 2009). For some, a feeling exists that these methods promote a one size fits all approach representing a particular view of best practice thus restricting the space for projects to explore their own design solutions. There are two problems which emerge from this:

1) a perception that the method promotes design solutions which represent poor value for client and developer therefore resulting in a lack of up take (one explanation 
for the failure of the BRE's Code for Sustainable Homes which was a BSAM for new build housing in parts of the UK).

2) a growing concern that by promoting specific options for design and construction that if not thought through then this can be linked with unintended consequences impacting on building performance as the project teams attempt to game play the credit system (Haroglu 2013; Bond and Morrison-Saunders 2011; Sheate and Partidário 2010).

The BRE stress that BREEAM is continuing to evolve and when applied correctly provides a framework to guide projects in sustainable design and construction promoting improvement and innovation in the way design is conceived. They argue that it is only when it is viewed as a standalone tool to audit compliance does the box ticking culture emerge resulting in incremental improvement above compliance. This realisation from the BRE marks a step forward but its success in promoting buy-in will be founded on the degree to which clients and project teams are able to engage with the sustainability criteria, the implications and to use the predicted and actual assessments to guide and promote a more sustainable approach. The consideration of actual sustainability performance marks a recent but important step in highlighting the growing number of buildings failing to deliver predicted design performance during POE (Atkins and Emmanuel 2014; Good Homes Alliance 2011).

With BREEAM evolving in this way, then accessing tangible information regarding sustainability at key decision points will provide an important stimulus for discussion amongst stakeholders (Mollaoglu-Korkmaz et al. 2013; Kaatz et al. 2006). Drawing on the evolution of Environmental Impact Assessment (EIA) it is possible to see how a framework approach can provide stakeholders the opportunity to engage in a transparent process and when appropriate enable them to actively shape the decisions 
taken promoting greater acceptance, mediation of views and learning with often the more sustainable option prevailing (Bond et al. 2012; Mathur et al. 2008). Drawing on this, the potential exists to expect a similar outcome as BSAM's such as BREEAM evolve to provide a framework around which projects can develop and importantly foster an improvement culture, encourage wider involvement, promote discourse, as well as facilitate learning and acquire new skills (Knox et al. 2014; Schweber 2013). Raising sustainability literacy as a means to promote change

At present uptake of BSAM's remains relatively small compared to the overall number of buildings delivered. As the view of BREEAM as a framework matures, it is important that project teams don't feel confined to the sustainability criteria and can still adopt a more individual approach to support wider sustainability criteria thus overcoming concerns about the limited holistic coverage. However, it is clear that only those who have a mature view of sustainable design and construction would have these concerns due to their higher levels of sustainability literacy. Such concerns are documented in the literature but outside projects such as London 2012 Olympics which adopted BREEAM within the wider One Planet Living Framework examples are few and far between (Desia and King 2006). BRE have established the BESPOKE version of BREEAM for complex projects to allow for a more individual approach but it is for progressive projects to establish their own approach which plugs gaps in the BRE's criteria and to supplement it with additional assessments (Cole and Valdebenito 2013; Xing et al. 2009; Cooper 1999). This should be encouraged as it reflects the ability to question and demand more from the BSAM, important to push the agenda forward and promote innovation. However, this can only happen when clients and professionals possess the levels of sustainability literacy to reflect this desire and showcase the change in culture. 
Stribbe and Luna (2009) argues that sustainability literacy is reflected in individuals who poses the skills and attributes needed to demonstrate emotional intelligence and technological appraisal whilst understanding that there is no one right way. If BREEAM is to contribute to helping project stakeholders improve sustainability literacy then two types of learning are required during the process to help foster firstly a holistic, multi-disciplinary understanding of the core principles and implications of sustainability on decisions and secondly to provide the opportunity for experiential learning (Kolb 1984) thus helping to provide real life transferable understanding of its implications for practice.

This research seeks to understand if the evolution of BREEAM towards a framework approach is succeeding in changing the way sustainability is being considered during the development of projects and in promoting the two types of learning required to promote sustainability literacy. This responds to calls by Bond and Morrison-Saunders (2011) and latterly Schweber (2013) for a lens to be cast on the implications of BSAMs on the practice of clients and professionals. This research takes the view that over time the issue coverage displayed in BSAM's will continue to evolve to a holistic approach and in its scope doesn't seek to challenge the validity or implications of the best practices being promoted.

\section{The importance of knowledge and its flow in delivering a framework approach}

If sustainability assessment is to evolve beyond the application of a building rating tool, its contribution to informing and shaping the subjective side of decision making is required. To achieve this, it is not just the outcomes from the assessments that need to be integrated into decisions but also the knowledge considered, generated and exchanged during the assessment process. The proposition of a more aligned approach with assessment practice playing an active part of project decision making is not new 
i.e. SMAZ addition to the Process Protocol (Khafhan et al. 2006) and RIBA's Green Overlay to the Plan of Works (RIBA 2011), but in practice outside of those actively embedded within the sustainability agenda it remains rare in contemporary projects.

Sustainability action plans demonstrated in examples such as London Olympics 2012 provide a clear structure around which assessment can be aligned with project decisions, highlighting the role of the project manager as a knowledge 'broker' in facilitating the alignment of the assessment with the project (Pemsel and Wiewiorab 2014), managing the flow of knowledge between project decisions, phases and teams.

If the BSAM is to contribute sufficient knowledge to help inform and enhance project decisions, project stakeholders need access to knowledge in a form which is at an appropriate level, form and language that is timely in order to share understanding, stimulate learning and to successfully mediate their various views on its implications for the project (Bond et al. 2012; Kaatz et al. 2006). This presents considerable challenges given the complex social processes associated in the development of a project (Harty et al. 2007). Sanchez and Morrison-Saunders (2011) have explored the role of knowledge management in the context of environmental assessment, but its consideration in the context of applying BSAM's within projects remains limited. Thomson et al. (2009) called for their application to be supported by a knowledge management strategy to facilitate alignment with the project's management and suggested its development to incorporate two recognised strategies: codification (focused on data management) and personalisation (focused around exchange of knowledge through personal contact) (Hansen et al. 1999). Together these strategies can facilitate the flow of different types of knowledge (explicit and implicit- including tacit) and ensure opportunities are presented for a dynamic approach to its exchange and transformation (drawing on 
Nonaka and Takeuchi 1995). This has the focus of enhancing the knowledge base of the team but also to promote lasting organisational and individual for the future.

Haddaway et al. (2017); Morrision-Saunders and Pope (2012) and Kaatz et al. (2006) have all cited the evolution of environmental assessment and its promotion of greater stakeholder inclusion with the associated flow of knowledge as providing transparency, mediation of views and importantly learning. Mathur et al. (2008) and Walton et al. (2006) advocated that BSAM's need to evolve to better reflect stakeholder contributions and recognise the wider learning their involvement can promote with Thomson et al. (2010) arguing that when mapped the flow of knowledge represents an indicator of their inclusion and participation. Project stakeholders have different knowledge requirements and preferences reflective of their role and experience with sustainability and its assessment, and understanding these will help bodies like the BRE consider how the evolution of BREEAM can respect this.

The emerging sustainability professional

The last decade has seen the emergence of the sustainability professional (advisors, consultants, assessors, managers) which has seen projects source directly sustainability expertise to supplement the knowledge base and literacy levels. Reflecting on renewed exploration of the role of expertise in construction management (Addis 2016) this research links to Stribbe and Luna (2009) arguing that these individuals provide the intelligence both emotional and technical through their training and also through their experience to supplement knowledge gaps, guide decisions to help clients deliver the best BSAM rating but also facilitate the two types of learning required to promote learning and improved sustainability literacy amongst project stakeholders. However, there remains a lack of empirical evidence over whether this hiring of 
expertise is realising this potential or is isolating knowledge from others through this increasingly professionalised role.

\section{Research aim and theoretical framing}

This paper builds on research conducted as part of the EPSRC funded Sustainable Urban Environments: Metrics, Models and Toolkits (SUE-MoT) project (2005-2009) where the authors explored the implementation of BREEAM within several construction projects. Whilst literature advocates the need for BSAM's to adopt a more holistic and inclusive approach aligned and supportive of project decisions; there remains a lack of empirical evidence exploring the implications and extent to which the evolution towards a framework approach is achieving the desired step change by helping to shape decisions, improve engagement with stakeholders and in contributing to raising sustainability literacy levels.

This research seeks to explore this through the theoretical frame of knowledge management which focuses on the process of creating, sharing, using and managing the knowledge and information of an organisation (Girard and Girard 2015). In this context, it focuses on the project as the organisation and explores the people, processes and any technology used to promote its management. The research argues that the flow of knowledge surrounding the consideration of the sustainability assessment is a key indicator to the extent to which the project is delivering the desired evolution of practice. The application of BREEAM will be explored through this lens with the knowledge flow mapped and the implications on the project explored before identifying the characteristics which aid its implementation. This lens enables knowledge to be viewed as a resource and that through its sharing it can foster understanding and promote organisational learning which can help to raise sustainability literacy amongst the stakeholders involved deemed so important to achieving the step change required. 


\section{Research strategy and methods}

\section{Constructivist grounded theory}

A constructivist grounded theory (C-GT) approach (Charmaz 2009) is adopted to guide the development of the research questions and strategy with a view to reflecting the context surrounding the application of BSAM's in practice. Adopting C-GT allowed the questions to emerge with the analysis responding to an early recognition that as well as the importance of prioritising sustainability in a project, that it was the potential for BSAM's to provide the stimulus for the flow of knowledge between project stakeholders which has the potential to improve sustainability practice, and this recognition shaped the research strategy and methods.

The research views knowledge and its flow as a key indicator of the effectiveness of the assessment to stimulate the desired knowledge sharing and interaction necessary for achieving the learning and cultural change required (Guo and Sheffield 2006). Process and knowledge mapping techniques are used to explore the dynamic project context and although these techniques have a functionalist tendency (Leblanc et al. 2015) it will enable paradigm interplay which is encouraged by many researchers supporting C-GT and the iteration between literature, policy and practice enabling the key questions to emerge as the research progresses allowing key themes to become visible (Willmott 1993; Hassard 1988; Gioia and Pitre 1990). C-GT permits a strategy to develop which is influenced by abduction (inductive and deductive) enabling alignment with a questioning approach with evolving research themes and lines of enquiry as the context is better understood through the mapping techniques (Saunders et al. 2015). This research is longitudinal representing four case study projects spanning 15 years with the first three case studies initially explored under a higher level research question which evolved requiring an iterative research philosophy to be adopted 
encouraging cross comparison of a number of methods and case studies. C-GT as opposed to purest interpretations of grounded theory permits this, supporting the various forms of analysis techniques utilised in the process and knowledge mapping (Suddaby 2006). The reflexivity over this timeframe enables the research questions to evolve and incorporate a changing external environment and to reflect and even revisit older projects with insight gained from contemporary projects.

\section{Case study approach}

The case study approach provides contextual focus for empirical inquiry and a suitable lens to explore the dynamics of practice and the flow of knowledge and decisions to be captured through process and knowledge mapping techniques. A multiple case study approach enables contrasting contextual experiences to be explored reflecting a developed criteria of attributes. The initial three case studies were followed longitudinally over a number of years continuing beyond the completion of the funded research with the authors seeking to understand the variations in management approaches in order to establish lessons for future practice. A fourth case study was included representing a contemporary example of best practice (opening 2016) and this enabled the research to reflect the evolution of BREEAM away from being simply a stand-alone tool and towards a framework approach over the course of more than fifteen years.

\section{Case study selection criteria}

A selection criteria was developed to promote a purposeful sample reflective of the transition in the BRE's aspiration for BREEAM and the maturing approach to sustainability enabling the implications on project management to be considered over the last 15 years. As a result, one case study required to represent the application of 
BREEAM as a standalone tool with no respect for this evolution within a reactive approach to delivering sustainability within a project. This could then be contrasted with three other projects which were recognised within the industry for reflecting best practice for their time period across the period. One should reflect a proactive client and project team who recognised the value of a framework approach but who were in the early stages of learning how it could be implemented in practice and where BREEAM would sit within this. This should be contrasted with a project where the framework was not only recognised but was provided as an overlay with a package of structural and process led measures to deliver this. This approach was beyond what was advocated by BRE and challenged the norms of the industry then and even today. To provide contrast a more contemporary project was sought which was reflective of recognised best practice reflecting the BRE's framework approach but similar in its aspirations to the second case study. Four criteria were established with three (in one case four) variants identified for each requiring to be reflected across the case studies.

Selection criteria:

(1). priority towards sustainability (compliance, good practice, aspirational)

(2). their approach to sustainability assessment (reactive, proactive, innovative)

(3). variation in the start date over last decade (early 2000’s, mid 2000’s, late 2000’s, early 2010’s)

(4). depth of sustainability criteria (basic, advanced, deep)

The case studies were selected as high profile projects within their local construction market lasting for a minimum of 3 years from inception to completion. Three of the projects all needed to be active in 2007 when the initial interviews were conducted due to the confines of the funded research, but the third criteria allowed for a project to be nearing completion and another in its early stages providing comparison 
between older (starting early 2000's) and more contemporary projects. The final case study sought to reflect contemporary practice recently reaching completion and recognised as representing good practice (i.e. BREEAM Outstanding certification). Four case studies were identified (illustrated in Table 1) and the variations in their characteristics deemed sufficient to showcase an evolution of practice over fifteen years important to explore the flow of knowledge to contributing to higher sustainability performance and long term learning. Insert Table 1: Case study alignment with selection criteria

\section{Steps of analysis using process and knowledge mapping}

Each case study was analysed through a series of steps (outlined below) reflecting process and knowledge mapping techniques, and an exploration of the contextual factors influencing the projects delivery and its assessment established through analysis of interviews with members of project team and supplementary grey literature.

(1) Establish a process map for the project (using RIBA Plan of Works 2007 phases)

(2) Identify phases and activities related to sustainability assessment

(3) Align sustainability assessment phases and activities with project process

(4) Identification of sources of knowledge (classified using categories established through research) for each assessment phase

(5) Development of knowledge map for each knowledge source, pathway, receptor for each assessment phase

(6) Examine maps to evaluate the alignment with project stages and effectiveness of the flow of knowledge between stakeholders

(7) Explore previous steps to examine the project management characteristics of leadership, structural, and cultural management 
(8) Consider the variations observed in selection criteria and consider implications for managing the assessment and requirements for a knowledge management strategy

\section{Interviews}

Semi-structured interviews established the basis to carry out the steps listed; with an initial phase of interviews with key individuals who can provide an overview of the project and its consideration of sustainability across its process. A review of grey project literature helped to establish the context and provided triangulation with the interviews and this included project management documents, planning documents, sustainability plans and reports, BREEAM assessment documents and others. It was during this phase where the first indication of the importance of the flow of knowledge around the assessment emerged. A second phase of interviews were undertaken with those who participated in the sustainability assessment either in its delivery or in the consideration of its outputs providing an insight into who was involved, their different roles and the knowledge dynamics associated with its delivery. Each interview lasted between 1-2 hours, with the roles of the interviewees displayed in Table 2 illustrating the two phases. Each of the transcripts were analysed using Nvivo software permitting different forms of coding to support emergence of key themes but also more structured coding supporting the categories formed in process and knowledge mapping. Contact was retained with the project and sustainability manager (if role existed) and follow up interviews every 6-8 months until the project was complete allowing for a complete process map. Additional grey documents were accumulated during these interviews including updates over time sourced during and after the completion of the project and were analysed. The fourth case study was approached as a sense checking exercise with 
an initial interview conducted in 2015, and later interviews during 2016-17 through to its occupancy. The steps outlined were followed to ensure consistency.

Insert Table 2: Stakeholders interviews across 4 case studies

\section{Approach to knowledge mapping}

Knowledge mapping was applied as a technique to not only understand the dynamics surrounding the flow of knowledge and its management but to also expose the wider structural and cultural dynamics surrounding the assessment. The technique has its roots in Epplier’s (2008) 'knowledge application’ approach which focuses on the type of knowledge applied to a certain process stage, but draws on Egbu et al.’s (2011) concern for specifics of the knowledge (documents, databases) and in observing the processes, roles and competencies of the stakeholders involved. The research follows two styles of mapping both considered by Vestal (2005) as 1) knowledge classification approach and 2) organisational network analysis. The latter is more visual and focuses on the flow of knowledge reflecting the relationships between stakeholders, identify who was involved in the assessment and define what role they played. From this it is possible to understand what knowledge the stakeholders hold, require and their preferred method of transfer. Coding around established categories of knowledge management were adopted to understand the types of knowledge allowing for the explicit (associated with codified knowledge) and implicit (including tacit, associated with subjective knowledge) to be reflected and considered through the lens of Nonaka and Takuchi (1995) Knowledge Transformation Framework which helps establish an understanding of the quality and impact of its transfer. The strength of the flow of knowledge around the consideration of the BSAM during the project and its transformation between explicit and implicit reflects a key indicator of its internalisation by stakeholders important to support increasing literacy levels. This approach to 
knowledge mapping is tailored to reflect the context rather than simply relying on one established technique and whilst applying functionalist structure to analysis it is conducted to support a wider C-GT approach by permitting cross examination.

\section{Identifying a suitable project structure}

Understanding how sustainability assessment relates to the phases of the project is an important first step in comparing the case studies. The process map reveals the depth and sophistication of the assessment process, highlighting through comparison the level of alignment achieved with the wider project's management. Appendix 1 shows the activities identified for each case study during the interviews, and aligns this to the project phases using RIBA Plan of Works 2007 as a common structure. This structure represented the contemporary version from the RIBA at the time the research was initiated, and respondents during the interviews in phase 1 were consulted over whether this was preferred to the project structure outlined in PMBoK. It was clear from these discussions that the later would hold wider recognition as a project structure with a greater number of professionals.

\section{Sense-checking workshops}

The structure was sense-checked during two workshops held in 2009 to explore the wider implications of the early findings from the first three case studies. The stakeholder maps for each project were discussed, with examples provided to showcase the nature of the emerging knowledge maps. The workshops sought to explore with senior professionals and experts to help shape the next phase of the research, contextualise and to elicit characteristics which could feed into practice to aid the flow of knowledge as BREEAM adopts a more framework approach. One workshop was held in London attended by 24 and another in Loughborough attended by 21 and across the two attending were senior executives from BRE, UK Green Building Council, 
BREEAM assessors, sustainability advisors, LEED assessors, executives from large and small contractors, architects focused on sustainable design and several academics invited as they were recognised as leading authors on the subject.

\section{Background and evaluation of case studies}

\section{Schools project}

A reactive approach to managing sustainability is demonstrated where the assessment was applied to check that building performance complied with the minimum sustainability targets set by the funders. Procured and managed through a Public Private Partnership, six primary schools in Scotland were delivered from inception in 2001 to completion in 2009; with the project deemed as a success on many traditional project management indicators (budget, time, quality, health and safety, user satisfaction). The client body aimed to align with what they saw as an emerging agenda in 2001, but when the project reached completion in 2009 it can be viewed as failing to keep pace with the evolving sustainability agenda and assessment practice. The process mapping revealed a simple linear progression of the assessment activities across the project phases illustrated in Appendix 2 with limited depth described for each activity in Appendix 1. A basic set of activities at the projects inception stemmed from the decision to apply BREEAM and then set an initial target of 'Good' with interviews revealing a reactive approach to sustainability and management through its limited consideration during project meetings and decisions. Figure 1 displays the stakeholder involvement grid revealing the client representative leading the process in its initial stages, but that the prime-contractor assumed the role of key decision-maker following their appointment at stage C. The stakeholders order reflects the perceived importance of those engaging in the BSAM's within the project based on the phase 1 interview and follow interviews in 
phase 2. Despite the design team and BREEAM assessor independently identifying areas to improve the design these were not realised or shared with each other due to the provision of no incentive in the contract to seek changes. The prime-contractor acted as the knowledge broker between the BREEAM assessor and the design team, and failed to pass on feedback from the assessor's preliminary assessment at stage D resulting in the design team being unaware that by focusing on a limited number of credits relating to energy efficiency (roof and window insolation) and water efficiency that a Very Good rating would be achieved. The restricted opportunity for discourse and likelihood to identify improvements in the design can be attributed to the prime-contractor obstructing the flow of knowledge. Interviews revealed that the prime-contractor viewed the assessment as an add-on, standalone assessment applied to perform an audit to ensure the Good rating agreed in the contract was delivered. The BREEAM assessor retrospectively concluded that this target rating was too low and that the client representative had not sought advice on its suitability or how to use BREEAM as a framework to help improve the emerging design and seek to improve the rating.

Insert Figure 1: Stakeholder involvement grid for Schools project

\section{University campus building project}

The Campus project represented a proactive approach to managing sustainability where assessment was applied with a view to improving the buildings performance during its development. The project started in 2006, with construction commencing in 2008 and completion in late 2009 (opened in 2010). Sustainability was placed as a priority from the outset and the project was managed through a PM consultancy employed directly by the estates department (reflected in the depth of activities in Appendix 1). The assessment was viewed as part of the development process with a 
desire to go beyond the BREEAM criteria offered and to explore how to make the assessment work better for the universities ambitious strategic sustainability objectives. The interviews revealed a client and wider team who reflect an emerging awareness of the role sustainability assessment can play in shaping the overall development of the building. The team were willing to be flexible, reflect and learn as the project progresses recognising the value of delivering a more sustainable building not just within this project but to help shape future campus projects. A sustainability advisor was appointed early in the project to help develop and deliver a broader view of sustainability and to guide the client towards a BESPOKE BREEAM criteria supported by additional assessment methods to reflect the university priorities (such as carbon accounting supported by through the Carbon Trust). The process mapping in Appendix 2 reveals an assessment process which is aligned with the project process and actively considered to help shape project decisions. A commitment to an improvement culture was evident in the consideration of the preliminary assessment conducted at stage D which showed a predicted BREEAM rating of Very Good but with the potential to improve to Excellent through targeted credits related to energy efficiency and biodiversity. The project meetings provided a high level of discourse and interaction between the team with a focus on understanding the implications of chasing these credits, benefits for the building and identifying design solutions. A reflective process was observed across the project process with the team regularly revisited and this is seen in overlapping assessment phases in Appendix 2. This is showcased in the level of engagement in the stakeholder involvement grid (Figure 2) between the broad project team across the process but the benefits are highlighted best around the consideration of the preliminary assessment and the targeting of additional credits for construction resource efficiency (from $\leq 7.5 \mathrm{~m} 3$ per $100 \mathrm{~m}^{2}$ (two credits) to $\leq 3.5 \mathrm{~m} 3$ per $100 \mathrm{~m}^{2}$ 
(three credits). The sustainability advisor suggested that these credits would help enhance the BREEAM rating and had a strong cost-benefit. The contractor was involved in these discussions and from a practical perspective were happy to support the changes required, and the client felt it represented a good lifecycle value for the project. Similarly, energy efficiency was an aspect where additional credits were initially sought and through discussion changes were identified where these could be achieved. The collaborative nature of the design process with its regular meetings supplemented by expert advice meant that opportunities for improvement were found with benefits discussed and a consensus reached. This can be seen in the increased consideration for passive design with 3 credits identified as being achievable through passive design analysis ( 1 credit), free cooling ( 1 credit) and low and zero carbon technologies (1 credit). These required changes to the design, but through energy modelling and collaborative discussions amongst the team the benefits were established for the lifecycle of the building. The other credits identified focused on ecological value with two additional credits found by employing an ecologist to conduct a survey and then responding to their recommendations. It is possible to see the high level of engagement in the project going beyond mere informing, with many stakeholders being actively involved in advising and being consulted. The extent of the improvement achieved when the project was assessed formally post-construction resulted in discussions with the BRE about whether to apply for an 'Outstanding' rating although this was not pursued partly due to the changes made to BREEAM in 2014.

Insert Figure 2: Stakeholder involvement grid for Campus project

\section{Regeneration project}

This case study represents phase 1 of the Greater Middlehaven Regeneration Programme in Middlesbrough, UK. Sustainability was a key part of the project vision 
from its inception, but it was with the appointment of the developer BioRegional Quintain Ltd (2010) in stage D where a comprehensive approach based around the One Planet Living Framework was applied by the developer to deliver the highest sustainability performance possible realised through a sustainability action plan (Desia and King 2006). This provides a clear vision, objectives, targets and assessment methodology with various methods applied across the project process to aid decisions. This marks a step-change in thinking, moving sustainability from being an add-on to current practice to its incorporation in every decision with an aspiration to deliver the best it can beyond legislative targets and as a core consideration at project meetings and routinely monitored. The developer aimed to challenge the project team and supply chain to be innovative in their practice, with the action plan providing explanation and guidance to support a change in culture.

Phase 1 started in 2008 but due to the economic down turn this was downscaled to the completion of only one block called 'Community in a Cube' in late 2011. Despite this, the building achieved the highest sustainability standards (Ecohomes Excellent target) however commercially it has failed to promote further development. In November 2011 BioRegional Quintain Ltd announced they would no longer trade, but BioRegional Development Group carrying on the One Planet Living framework approach acted as the sustainability consultant for the London 2012 Olympic Games and applying the same management principles. At Middlehaven, BREEAM was applied, but as one of many assessments such as ecological footprints for both materials and future residents, carbon footprint, travel assessments, health and wellbeing assessments, social and economic impact assessments (outlined in Thomson et al. 2014). The approach has been praised but concerns have been raised about the 
commercial viability for future projects of applying such a holistic view of sustainability (Daothong and Stubbs 2014; Epstien et al. 2011).

What sets this project apart is the broad engagement around sustainability and its assessment with wider stakeholders such as community groups, as seen in the stakeholder involvement grid in Figure 3. Stages A to D (managed by Teesside Regeneration Company) experienced wide stakeholder engagement and from stage E onwards the developer actively sought to engage stakeholders in the consideration and delivery of assessments for planning, design, post practical completion, and postoccupancy as part of a wider methodology based around their sustainability action plan. Highlighted was the role played by specialists within the developer's team specifically to manage the delivery of the action plan across the project led by the sustainability project manager and supported by their team (sustainability integrator, and assessor). Their expertise provided an understanding of the overall aim of the action plan, but also technical knowledge related to the specifics of the individual assessments and their requirements. It was apparent that engagement levels went above simply informing with many stakeholders engaged in advising and being consulted about the assessment and its implications.

Insert Figure 3: Stakeholder involvement grid for Regeneration project

\section{College building project}

This project represents the delivery of a contemporary low carbon building for a Further Education College which was completed in 2016. The research sought a comparator project which was proactive in approach to managing sustainability and was reflective of best practice. This project was one of the first to achieve the BREEAM 2014 new construction assessment rating of 'Outstanding' and was nominated as a finalist for the BRE awards in 2016. It represents the closest to the framework approach 
being currently advocated by the BRE with BREEAM being central to the management of sustainability and its assessment. A two story steel frame building designed for teaching sought to reflect the Colleges sustainability ethos and polices, with a commitment to embed these across the stages of the lifecycle. They recognised that embedding sustainability in the design process was key to delivering the intended passive design strategy focused on utilising thermal mass and enhanced technological efficiencies with a building management system (BMS) to control and monitor the building. The appointment of a developer who specialises in building services reflects this commitment, in addition to the inclusion from the outset of a sustainability advisor as a project partner to provide advice around the BREEAM criteria. The building's BMS is linked to the wider campus's BMS to aid the management of the building by estates department and a focus placed on encouraging positive energy behaviour through the display of the results to building users. This shows a commitment to managing the whole life of the building and retains sustainability during the project phases and beyond.

A target BREEAM rating of Outstanding was applied from project inception and formed the basis for the design and project decisions which followed (Appendix 1). This shaped the criteria for selecting the contractor and wider team, and success was determined by achieving an Outstanding award in the completed building. BREEAM formed the framework around which the design and wider project could develop, with strong leadership provided from the client body to the extent that during the design process it was widely reported that the functionality of the building for teaching was compromised to protect the Outstanding rating. It was observed that preliminary assessments were applied at a number of stages to ensure the delivery of the rating as opposed to providing an opportunity for improvement as in Campus project. 
The College project showcases the role of a sustainability advisor brought in from the outset as a project partner to guide the team in the application of BREEAM and to help achieve the Outstanding BREEAM rating. The stakeholder involvement grid displayed in Figure 4 reflects a similar number of stakeholders being engaged than in the Campus and Regeneration projects but it is possible to observe a lower level of those consulted in shaping the approach of sustainability within the project (i.e. what level to aim for, how to go about it, the implications for the project). The interviews did not reveal this as a problem for the project team, as they felt actively informed and displayed confidence that those guiding and advising the sustainability direction of the project were doing a good job. The team whilst not being consulted to the same degree displayed a stronger satisfaction of the merits of the sustainability agenda with many displaying experience from previous projects which achieved high BREEAM ratings. This confidence can be seen in the willingness to accept the innovations in design and technology, and in fewer stakeholders feeling the need to get involved in the detail around the assessment to the extent seen in the other two case studies.

Insert Figure 4: Stakeholder involvement grid for College project

\section{Analysis of the knowledge mapping}

Understanding the sources of knowledge and being able to classify these is an important aspect of preparing for knowledge mapping. For each assessment phase different types of knowledge were identified i.e. explicit (e.g. document based) and implicit (be it values and requirements of stakeholders, expert knowledge; or tacit knowledge provided by individuals past experiences). Appendix 3 illustrates an example of the classification of knowledge sources for the Campus project during the 
selection of sustainability issues, but this was replicated across all four phases for each project revealing a contrast in the number and variety of explicit sources drawn upon by stakeholders. The Schools project noticeably drew on around 50\% less explicit sources than the Campus project, 70\% less than the Regeneration project and about 50\% less than the College project. Another important observation was the degree of similarities in the levels and patterns observed for the Campus and College projects. Greater variation was observed in the support provided from implicit sources. The Campus, Regeneration and College projects reflected a reliance on implicit sources of knowledge both in terms of expert knowledge from advisors and consultants, but also tacit knowledge emerging from drawing on previous stakeholder experiences. The Schools project displayed a low reliance for expert and tacit knowledge across all assessment phases, partly due to the lack of awareness and low literacy levels held within the team, and also due to the isolation of the BREEAM assessor in relation to the communication pathways which restricted their ability to share expertise with other stakeholders.

The next step of the knowledge mapping was to identify what knowledge was held by each of the stakeholders during phases of the assessment and the drivers which exist to stimulate the flow of knowledge between them. These were contextual for each case study, but analysis revealed that there was a high degree of similarity resulting in a generic set of drivers which were ranked with respondents during follow up interviews and displayed in Table 3.

Insert Table 3: The top 7 ranked key drivers stimulating knowledge flow for the phases of sustainability assessment

The research acknowledges that different knowledge mapping techniques have advantages in helping reveal different patterns captured by the two types applied 1) 
knowledge classification approach illustrated in Appendix 3 and 2) a visual organisational network approach. The knowledge sources could then be mapped with those stakeholders who held it, the pathway which was described for its transfer, the stakeholder who received it and the driver with which its flow was responding. Table 4 demonstrates this for the Campus project revealing the strong reliance on expert knowledge during issues selection. This exercise highlights the range of stakeholders who can contribute to the decision-making process, and the need for various exchange mechanisms to facilitate transfer through a mix of formal and informal pathways. Analysis shows that the Schools project relied on a smaller number of knowledge sources, resulting in fewer stakeholders engaging and less exchange mechanisms resulting in a reduced flow of knowledge. Those managing the process were seen to have limited awareness or pressure to deliver on the key drivers and therefore lacked the necessary stimulus to exchange knowledge. The other three projects reflected greater awareness of the drivers and with stakeholders actively seeking the knowledge to help their understanding or even aid decisions. The College project revealed that as the stakeholders display more experience with BSAM's they feel able to contribute due to their ability to draw on their own experiential learning and therefore draw on less explicit sources such as guidance documents.

Insert Table 4: Knowledge map for expert knowledge during issues selection (Campus project)

A more visual network based technique better demonstrated the dynamic nature of its flow and better reflects the points of its transformation when supported with the narrative from the interviews. Figure 5 illustrates this style of knowledge map focusing around the assessment phase and drivers which stimulated the flow of knowledge. The 
example provided is a knowledge map for the driver 'project constraints' (for assessment phase) for the Campus project showing key-decision maker, knowledge sources and holders and the pathways of transfer and recipients. This example helps to tell the story of the client representative drawing on the sustainability assessor to guide the process using their expert knowledge based on training and experience. It also shows the sustainability assessor liaising with the developer to exchange knowledge about how to overcome challenges set by the project context. Exchange of knowledge is also observed between the assessor and the tool developer (BRE) showing their role in advising especially for BESPOKE criteria. The client representative also engages with the project board regarding the assessment, in addition to consulting explicit sources of knowledge such as project reports and documents. A bio-directional flow of knowledge between the stakeholders with the right ones engaging with each other at the right time with appropriate knowledge is clearly evident. The maps highlight the importance of considering explicit sources during decision making, but significantly illustrate the importance of implicit sources exchanged through two-way discourse between project stakeholders. The Campus project displayed this organically partly due to the inclusive project environment promoted by the client body with the team encouraged to seek knowledge and learn from each other through informal pathways, as well as formally through the project meetings. Figure 5 is just an example, but a similar pattern was found across all the phases of the assessment.

Insert Figure 5: Example knowledge map for the driver of project constraints during assessment phase (Campus project)

In contrast, Figure 6 provides an example for the Schools project reflecting the same driver of project constraints for the assessment phase revealing that although there 
is a web reflecting an active flow of knowledge, closer analysis reveals a one-way flow with the prime contractor at the centre. There is no opportunity for feedback or transfer of implicit knowledge to the design team or other stakeholders to help improve the design due to the blockage caused by the prime-contractor. The sustainability assessor is very much outside of the wider web of knowledge, and for important stakeholders like the designers they are not encouraged to engage in a two-way flow of knowledge with the prime contractor about the assessment.

Insert Figure 6: Example knowledge map for the driver of project constraints during assessment phase (Schools project)

The Regeneration project displayed similar patterns to the Campus project across the maps but was more structured with the developer aiming to formalise a project environment which promoted meaningful exchange of knowledge around the sustainability action plan. Whilst the College project shared many similarities, it was apparent that a higher level of sustainability literacy existed resulting in a reduced number of explicit sources being consulted. An increased frequency of informal interactions was observed between stakeholders at key points but especially during BSAMs implementation and in the consideration of results. The interviews reinforced the point that in the more contemporary projects, stakeholders felt more comfortable to contribute based on their experience from previous projects again reflected through the bio-directional arrows in the maps across the later three projects, highlighting the value of experiential and social learning.

The knowledge maps helped to emphasise the role played by sustainability experts, such as the sustainability advisor, employed to contextualise their expertise drawing heavily on passing implicit knowledge. This role was different to the BREEAM assessor, and in the Campus and Regeneration projects was seen as novel with the later further 
supplementing this with a sustainability project manager and a site based integrator. The College project reflects the standardisation of this professional role in progressive projects and an acceptance of their guiding role.

The dynamic nature of knowledge, its transformation and opportunities for learning Using two different styles of knowledge mapping around 1) knowledge classification and 2) a visual network approach helped to explore patterns in a complex web highlighting not only the need for decision makers to identify the right knowledge source and ask the right questions, but to ensure that effective pathways are provided to ensure that a wide stakeholder group can make a contribution or at least be exposed thus promoting learning. In all of the case studies, it was clear that a complex flow of knowledge takes place which is dynamic by nature, ever changing and with the pathways of exchange existing in multiple forms maximising the flow and potential transformation of knowledge greatly enhanced the assessment process (aligning with Nonaka and Takeuchi 1995).

Socialisation was a key component within all but the Schools project where the opportunity was restricted by the project structure. The Campus and Regeneration projects produced the most complex maps highlighting the high level of knowledge exchange between stakeholders reflecting high levels of socialisation resulting in the transformation of knowledge from tacit to tacit, but then the internalisation of this knowledge within the stakeholders to be transferred back into explicit knowledge through documentation. This reflects evidence of increased understanding and learning amongst stakeholders. In the Campus project it is possible to see directly the benefits that socialisation had in relation to the way the preliminary assessment was considered by the team as they worked with the sustainability advisor to target specific credits for improvement in order to achieve the Excellent rating. The frequency of meetings and 
their inclusive nature provided the context around which team members could explore together the benefits and implications for the design of chasing specific targets. The socialisation with each other, as well as the access to the expert knowledge of the sustainability advisor meant that decisions were made together fostering social, mutual and on an individual level experiential learning. In the Regeneration project, socialisation was a recognised component of the project, with stakeholders encouraged to engage in aspects of the project which would not traditionally involve them professionally with a view to learning and potentially contributing. The College project displays a slightly reduced level of socialisation with project stakeholders becoming more comfortable with the use of sustainability advisors to supply expert knowledge directly to shape project decisions. This has the potential for stakeholders to stop asking questions and that this could diminish the socialisation and therefore lessening the wider learning experience through a lower flow of tacit knowledge. Whilst this wasn’t seen as a critical issue in the College project, interviews with team members did suggest that it could be a problem moving forward.

\section{Discussion and recommendations for future practice}

Analysis of the first three case studies revealed themes which were explored during the two workshops held in 2009, and though interviews continuing up till 2017 enabling reflection on contemporary practice and the College project. BSAM's are slowly becoming accepted in practice but four key elements were identified as necessary to facilitate its further evolution: 1) sustainability leadership within the project; 2) a framework approach aligned with project management; 3) an improvement focused culture and engagement and 4) a management strategy for promoting knowledge flow. 


\section{(1) Sustainability leadership within the project}

The project lead has a key role to play in providing leadership for project sustainability and the priority placed on the role of the BSAM. Evidence from across the case studies showed that depending on the project stage this can come from the client representative or project manager. The Schools project demonstrated a lack of sustainability leadership both in the early stages through the client representative's lack of understanding and in later stages when the prime-contractor displayed apathy for the agenda. This can be contrasted with the passionate championing of other important agenda's such as health and safety or site waste management. Opoku et al. (2016) reflected on the fact that leadership for sustainability in construction often fails to move from strategic to operational focus potentially leading to its de-prioritisation in projects. Quinn and Dalton (2009) argue that achieving leadership at an operational level depends on the ability of the leader to frame the concept for the team and build capacity in their system and culture to support it. This was clearly lacking in the Schools project, but can be found in the other three case studies. Stoughton and Ludema (2012) argue that setting the sustainability context is key in the initial stages and that managers need to translate the organisations sustainability goals into manageable tools and programs so that it transcends across organisational, functional and individual levels. The Regeneration and College projects both demonstrated leadership which translated the concept across the levels with management protocols and tools best illustrated by the sustainability action plan in the Regeneration project. The more organic approach found in the Campus project was the result of the project leaders learning as the project developed, however the provision of a strong context in the initial stages enabled the team to understand the rational for the direction taken and fostered capacity to support the process. The project leads displayed leadership through their ability to interpret how sustainability was linked with their project and wider systems, and this helped the team 
embrace organisational change; a trait found also in the Regeneration and College projects. These were concepts explored by Metcalf and Benn (2013) who argued that the complexity of sustainability and its implications for organisations requires leadership which can achieve complex problem solving. This requires a high level of sustainability literacy from either the project lead or through its provision by the advisor.

A key aspect of successful leadership was observed to be the recruitment of project teams who are committed and can display literacy for sustainability. This can be seen in the Regeneration project through the selection of an innovative developer with a formalised sustainability vision, and in both the Campus and College projects where team members were selected on the basis of a track record and willingness to engage. The selection of a team who were likeminded and 'get' sustainability provides an important basis from which to influence others (Robertson 2017). In this case it removes unnecessary resistance and facilitates the project lead by bringing in expertise to help deliver complex ideas. The recognition of drawing on experts in the form of sustainability advisors to fill knowledge gaps demonstrates a strength in leadership and aligns with the findings of Egbu et al. (2005) who stressed their importance to ensure organisational sustainable competitiveness.

The Campus and College projects shared many similarities, with the more contemporary project revealing a shift in leadership which is less about changing culture and more about progressing an increasingly accepted view of sustainability as a project requirement. The Campus project reflected leadership focused on changing culture within the industry, an aspect formalised in the Regeneration project. Rees (2009) and Robinson and Cole (2015) stress the importance of leadership in changing the culture around sustainable construction, and this is re-emphasised in Cooper (2018). 


\section{(2) A framework approach aligned with project management}

The move by the BRE to promote a framework approach around which BREEAM can help promote sustainable practice was very much observed during the later three case studies. The Schools project was reflective of practice in the early 2000's where assessments were viewed as a project add-on applied as an auditing tool to ensure compliance with funding requirements. The Campus and Regeneration projects represent those starting in 2008-09 with assessment beginning to be regarded in good practice projects as aligned with the projects development. The Campus project reflected a client body who understood this, but it was the sustainability advisor who helped them utilise the assessment framework (indicators and tools) and ensure it was aligned with the key points in the project process. The Regeneration project demonstrated a management approach specifically developed with the assessment at its heart supported by the sustainability action plan and its role as a core project document. The One Planet Living Framework provided a common set of indicators to consider across all project phases, with the action plan outlining the implications for the project in a language which was tailored for their professional needs and project phase. This approach differed from the Campus project, as this was a pre-existing approach trialled on other projects. The action plan was further supported through a project intranet to facilitate the exchange of explicit sources of knowledge and ensuring access is provided to project team members. This approach at the time was unique and promoted by an organisation who were trying to carve out a niche in the market.

Devuyst (1999) outlines that sustainability assessment should be applied as a methodology that can help decision makers decide what actions they should take or not in an attempt to make society more sustainable. Such a role can be seen in the adoption of the framework approach adopted within the College project which set to deliver best practice but which was aligned with convention without challenging the paradigm or in 
seeking to add any unique criteria (as witnessed in the Campus project). Concern was raised that if BSAM's are applied in too uniform a way they will reduce the need for stakeholders to question the implications for the building's design. Being able to question and explore was observed as a key benefit in the approach adopted in the Campus and Regeneration projects resulting in improved sustainability outcomes. The Campus project reflected a more organic approach with a client who wanted to progress their own practice by learning from a sustainability advisor and encouraging a questioning culture within a framework approach. The Regeneration project sought to be innovative through a new paradigm inclusive of but beyond BREEAM around a framework reflecting One Planet Living.

Oliver and Pearl (2018) recent publication re-emphasised the importance of viewing assessment as a process based approach stressing that there are wider benefits beyond simply the delivery of a more sustainable building. Quinn and Dalton (2009) argue that broad and deep stakeholder engagement is essential within organisations to establish the capacity within the system and culture of an organisation to deliver sustainability. Care needs to be taken that the framework emphasises the benefits of the process ensuring that engagement retains the ability to question and innovate in this context with the framework

\section{(3) An improvement focused culture and engagement}

The research found that a framework approach can realise its potential, but only if an improvement culture is created which promotes the opportunity for knowledge to flow thus enabling learning opportunities. The relationship between continuous improvement and sustainability has been explored in a number of contexts within the literature (Eccles et al., 2014; Bertels et al., 2010), with Linnenluecke and Griffiths (2010) arguing that fostering such a culture is a complex task given the varying 
organisational objectives. Silvius and Schipper (2014) highlight this challenge in the project context arguing that sustainability conceptually challenges and often opposing principles of project management. The Campus project provides an example where the traditional indicators for success changed to different criteria reflecting cost, quality and time but with the addition of concern for the projects wider impact. This sparked a knowledge centred culture with like-minded professionals selected to work together to achieve the best they could within the envelope presented. The Regeneration project was more prescriptive in its approach but a similar culture was promoted supporting social, mutual and experiential learning amongst stakeholders. This can be evidenced in both projects through the knowledge maps reflecting high levels of sharing revealing its dynamic and often opportunistic nature with interviews regularly citing the value of allowing the stakeholders to enjoy accessibility, openness and transparency during decision making as it creates opportunities for improvements but also supports individual and organisational learning. This aligns with Quinn and Dalton’s (2009) understanding that deep stakeholder engagement is the key to promoting sustainability within organisations; a connection made in the context of BSAM around mutual learning by Mathur et al. (2008). Engaging the stakeholders creates an interest and promotes a desire to improve with a move towards co-production of knowledge and sharing of decisions; a concept recognised for a long time within environmental assessment (Pope et al. 2004) and is a key contribution too double and even triple loop learning (White and Noble 2013).

The engagement hierarchy (inform, consult, involve, collaborate and empower) provides a useful lens around which to reflect on the extent to which this is achieved. It is possible to view the experience of both the Campus and Regeneration projects and showcase an open, transparent and collaborative environment where stakeholders feel 
they can participate and contribute and in some instances get close to empowerment. The Schools project on the other hand reflects a low level of engagement which can only be classified as informing. The College project provides a key point of interest as it reflects strong engagement but it is possible to observe that in terms of the hierarchy this is lower than the Campus and Regeneration projects reflecting involvement and in some cases collaboration in the consideration of sustainability and its assessment. This is reflected in the reduced flow of knowledge through the knowledge maps, and is another indicator of a team with a higher sustainability literacy baseline who are happy to allow sustainability advisors to provide expertise and thus lowering the need for high level engagement. Kohler (2018) argues that new knowledge will increasingly be coproduced through trans-disciplinary approaches due to the decreased levels of certainty as project decisions get more complex, a point further emphasising the need for promoting more developed forms of engagement.

Sustainability advisors enable the project manager to be more strategic and less focused on the detail surrounding the BSAM's. The more contemporary project reflects the mainstreaming of the agenda but caution emerged during interviews over the willingness to let the sustainability advisor simply take the lead and to not question their advice. This was contrasted with the Regeneration and Campus projects stakeholders feeling of empowerment to ask questions and even challenge advice which was provided as part of their learning process. This reflects the increased acceptance of the role of expertise, but opens the potential for blind acceptance from stakeholders therefore limiting the opportunities for innovation and learning.

The project manager is identified as playing a key role by encouraging an improvement culture, determining the level of engagement and in maximising the opportunities for learning. A key attribute of a project manager is to be able to 
understand the needs of the stakeholders and to facilitate the flow between them and enable pathways to develop (Freeman, 2010). It was apparent in this research that the project managers have played a key role in achieving this in the Campus, Regeneration and College projects breaking down some of the perceived norms in construction which are often used to limit innovation and new ways of thinking. Sage (2016) argues that often non-human expertise held in existing policies, processes and technologies act to constrain knowledge flows from progressing sustainable practices. This can be seen in the Schools project, and to a certain extent in the Campus and College projects where the BSAM's were still applied in the context of conventional practice. The Regeneration project is where the developer and project management were able to break down the traditional ways of doing things and reinvent the non-human knowledge by new protocols and ways of doing things.

\section{(4) Management strategy to promoting knowledge flow}

The knowledge mapping revealed a dynamic flow of knowledge reflecting a mix between explicit and implicit sources and where successful a bio-directional exchange between stakeholders. The case studies illustrated that when successfully managed suitable pathways present both formally structured and permitted organic informal engagement. This is important for not only ensuring that the decisions taken are inclusive, transparent and agreeable; but also to ensure that the decisions made are supported by appropriate knowledge which is accessible and interpreted effectively by relevant stakeholders. Enabling stakeholders to contribute to the flow of knowledge on their own terms is the most effective and democratic way to achieve this, as opposed to management assuming which knowledge they need or even who they presume hold it. This aligns with van Buuren’s (2009) call for inclusive knowledge management as a key part of collaborative approaches. 
The Schools project highlighted that when barriers were placed on the flow of knowledge between the BREEAM assessor and the design team this limited the potential to improve sustainability performance of the schools but also withdrew the opportunity for learning. Indeed, analysis of the other case studies revealed that ensuring discussion and access to the flow of knowledge provides often unexpected paths to knowledge (even for those who hold it) highlighting the importance of an inclusive culture which encouraged questioning. These are principles stressed by du Plessis (2007) in the context of knowledge management in promoting innovation. The contrast between the Schools and other projects highlights the importance of a mix of formal and informal pathways to provide the dual needs of structured knowledge provision as well as facilitating opportunistic contributions and exchanges.

The Campus, Regeneration and College projects highlight the connection between a strong flow of knowledge surrounding BSAM's and resultant improvement in the sustainability performance of the buildings. The potential this offers requires that consideration is given to a knowledge management strategy established around an integrated codification and personalisation strategy (Hansen et al. 1999). Although this terminology was not cited during the interviews, it was possible to see recognition of the importance of ensuring that explicit knowledge was codified and available both when required and to effectively capture, store and enable retrieval of appropriate knowledge when generated during the assessment process. The Regeneration project highlighted the project intranet as going some way to enabling access on an ad-hoc basis and in its ability to store knowledge in a variety of forms. A personalisation strategy is also necessary to enable the access and opportunity for a range of stakeholders to participate when necessary and through socialisation. By identifying the project manager at the heart of most of the knowledge maps in these three case studies it 
reveals their key role in identifying the relevant stakeholders; in understanding their role, preferences and identify suitable mechanisms to facilitate their engagement with the process. The mapping revealed that this can occur through a mix of formal meetings, workshops, seminars, informal meetings, and the encouragement of informal contact even through social networking capabilities through discussion boards and virtual meetings. Maximising the opportunity for knowledge to be exchanged in a number of forms, to allow stakeholders to choose which they wish to participate in (as long as confidentiality is not breached). The Regeneration project reflected a growing alignment with good practice in knowledge management and recognition of the value of a commitment to socialisation such as meetings, workshops, informal discussions etc.

The key benefits of achieving a high level of engagement and a strong flow of knowledge between stakeholders is the raised potential for learning which was demonstrated in Campus and Regeneration projects. A key indicator of this was in the high level of transformation of knowledge which was witnessed aligning with the framework proposed by Nonaka and Takuchi (1995). This transformation can be demonstrated in numerous ways but the best example can be through a stakeholder who is able to receive tacit knowledge through exposure to being present at a meeting considering BREEAM and its implications for the developing design, and at a later date being able to demonstrate their learning by being able to write about it in a project report and then advise a team working in another project.

Addis (2016) provides caution to reliance on knowledge purely sourced from socialisation as it could be ill informed or be restrictive in its implications. This research suggests that the sustainability advisor plays an important role in sense checking the assumptions of other stakeholders in line with both the principles of sustainability and their training and experience. The more stakeholders are exposed to the flow of 
knowledge; their level of sustainability literacy should increase. The one inhibitor to this is when the advisor becomes isolated from the team with little influence on shaping the project as in the Schools project or as in the College project where the team relied on their specialist knowledge with the side effect that it dis-incentivised their desire to ask questions or learn. In the College project the team trusted the sustainability advisor, their knowledge and judgement resulting in a positive outcome but this will not always be the case as pointed out by Mogendorff (2016). This final point should be considered in relation to Chan's (2016) observation that expertise is not static but is interactional, intuitive, incidental and continually evolving in the context of practice. Sustainability professionals need to continue to evolve and retain their currency as experts and a key way to achieve this is to be involved in a flow of knowledge with project stakeholders so they can be shaped by the realities of practice. This needs to be seen in tandem to their role as a guide, to sense check and promote the necessary experiential learning amongst stakeholders important to promote their sustainability literacy levels.

\section{Conclusions}

The research explores the evolution of the application of BSAM's and specifically BREEAM in the UK as practice seeks to respond to calls to evolve away from a traditional view as a stand-alone tool independent of project decisions and towards a framework approach which can contribute to shaping the projects development. The mid 2000's saw a consensus from the likes of Cole (2005) and Kaatz et al. (2006) that BSAM's needed to evolve but only limited empirical evidence regarding the extent of the transition has been achieved with enquiry instead focusing on the coverage of indicators, application to different contexts, and on building performance largely neglecting the need to consider the implications for project management, wider role in promoting change and in encouraging learning. Recent 
publications by Cooper (2018), Lowe et al. (2018) and Oliver and Pearl (2018) have reemphasised its importance. BREEAM as the BSAM with the longest development history has shown arguably the earliest commitment to the framework approach whereby good practice is promoted to move beyond compliance with project stakeholders supported at key points in the projects development.

By exploring these case studies through the lens of knowledge management, it enabled for knowledge and its flow to be viewed as a key indicator of the effectiveness of this transition in promoting understanding and learning through stakeholder engagement, mediation of views and knowledge transfer. Reflecting on the engagement hierarchy it was possible to observe that the Campus and Regeneration projects reflected the strongest levels of engagement between stakeholders across the projects development with the assessment. They had the most developed knowledge maps, involving the most stakeholders at key points in the project and this resulted in projects which were able to identify opportunities to improve their sustainability performance but importantly resulted in the highest level of observable knowledge transformation. This aligns with the Knowledge Transformation Framework of Nonaka and Takuchi (1995) highlighting particularly the value of promoting socialisation between project stakeholders as key to promoting the opportunity for knowledge transfer and the benefits of social, mutual and experiential learning advocated by the likes of Bond et al. (2012) in the context of environment assessment and Mathur et al. (2008) in the context of BSAM's.

Four key themes emerged reflecting the importance of sustainability leadership in setting the context, the need for framework approach around which the BSAM can shape project decision making, the creation of an improvement culture formed around engagement, and finally the development of a knowledge management strategy. These 
are all necessary to facilitate the important flow of knowledge which emerges when stakeholders are able on their own terms to reflect on their professional role, knowledge requirements and their potential to contribute knowledge to help shape the process as they see fit.

Great strides have been made in the last 15 years with the mainstreaming of sustainability and the more aligned role played by of BSAM's such as BREEAM in progressive projects. However, three concerns exist moving forward:

\section{1) Ensuring that BSAM's contribute to decision making and don't determine them}

As BSAM's become more prominent in practice they have the potential to establish a standard for sustainable development within the construction industry. This has many benefits enabling alignment with national building regulations, common best practice, ability to benchmark and encourage knowledge sharing. However, this research argues that in developing the BSAM's of the future, tool developers shouldn't create an approach which prescribes a sustainable building. The benefits of the framework are it seeks to be a contributor to decision making and not a determinant. There is no one way to design and construct a building, and aligned to this there is no right way to deliver the principles of sustainability in that context. As a consequence, the only way to progress this agenda is by developing stakeholders and professionals who have higher levels of sustainability literacy able to navigate the challenge of delivering sustainable buildings that retain the principles of the concept but which respect practical realities and contextual limitations. The framework approach provides the opportunity to encourage engagement amongst the stakeholders so they can contextualise the sustainable design and construction recommendations around the requirements of their project. Promotion of standards through BSAM's has a part to play but if too perspective then a box ticking 
culture is promoted which stifles innovation and runs the risk of inappropriate solutions for the context of the building. This is a difficult tight rope to walk, and has the potential for future tensions. BSAMs' need to reward through their ratings systems to encourage innovation, learning and best practice, and ultimately encourage the design of as sustainable a building as is possible within the context presented. This aligns with Oliver and Pearl (2018) who argue that context and players (stakeholders) can't be divorced from tools. The Regeneration project demonstrates where a developer with a high level of sustainability literacy is able to adopt a more holistic interpretation of sustainability in the governance of their project but are also able to accommodate a BREEAM assessment within it. Sustainable professionals have the potential to facilitate this, but BSAM's have the potential to provide a framework around which wider construction professionals can learn and achieve this through social, mutual and experiential learning.

\section{2) Overcoming stagnation by achieving stakeholder empowerment}

Despite the move towards a framework approach increasingly being embraced in progressive projects it is apparent there is a question about how to increase the uptake amongst a wider number of projects. As it is unlikely that BREEAM will become a requirement in the UK any time soon, there is a question about how else to achieve increased engagement with the scheme. This research highlighted the importance for enabling project stakeholders to engage with professionals who have stronger levels of sustainability literacy with a view to passing on their emotional and technical intelligence as well as enabling experiential learning which can benefit future projects. This is why it is important that in engaging with BREEAM that project stakeholders move beyond mere involvement and move closer to collaboration and ultimately empowerment to maximise their learning. Through this they foster an association with 
how the BSAM helped shape the project for the better and become an advocate. This level of engagement can be seen in the Campus and Regeneration projects with stakeholders taking away a strong learning experience which has seen them go on to engage in more projects which involve BREEAM.

3) Overcoming the potential for engagement levels to drop as the sustainable construction agenda matures

Concern exists that as BREEAM becomes more established that if the framework fails to promote a learning and improvement culture then the benefits promised to change practice and promote innovation will not be realised across the wider industry. It is possible to argue that the College project represented a maturing view of BREEAM but a more conservative view of sustainability than the organic perspective of the Campus project or the radical approach of the Regeneration project. In the later it's the aspiration demonstrated to aspire to deliver as sustainable a building as possible using its own framework supported by innovative and existing assessment methods. Whilst achieving an Outstanding rating in the College project, there is a concern that many of the project stakeholders were not as engaged as their counterparts in the Campus project in particular. Despite displaying a higher level of sustainability literacy, there was not the same hunger to learn and ask questions thus losing the urgency of the situation which is a key concern of Rees (2009) and in Cooper (2018). There is a clear need to aspire for empowerment in order to promote the desired experiential knowledge as advocated above. The sustainability advisor played a key role in the College project and whilst the increased acceptance and trust in their knowledge is an important step forward there is a need to ensure that this doesn't restrict the need for project stakeholders to question and learn amongst the wider project stakeholders. The experience found in the Campus and Regeneration projects showed that expert 
knowledge has a key role in helping to engage project stakeholders and exposing them to their knowledge and explaining the implications. A framework around which engagement can take place aspiring to collaboration and even empowerment is where the future of BSAM's needs to head in order for learning and the innovation to prosper.

\section{Limitations and future research}

With the research focusing on the application of BREEAM with case studies all in the UK, it is not possible to generalise specifically whether other international BSAM's would experience the same patterns found in this research. However, with LEED sharing similar developmental roots to BREEAM it can be speculated that lessons found in this research should be transferrable although additional research is required for a comparative study. DGNB due to its more quantitative approach with greater focus on the lifecycle would require a more in-depth study to explore differences.

This research represents a starting point to exploring how BREEAM is applied in practice and the potential exits to explore this through a wider sample. Four case studies provide a purposeful sample and a more representative sample of the breadth of practice would aid the progression of deeper understanding.

The research contributes to the growing understanding of expertise in construction management represented through Addis et al. (2016). Sustainable construction provides a strong context given the emergence of the sustainability professional and their influence on promoting of learning amongst stakeholders. Further exploration of the requirements to promote sustainability literacy levels provides a path for future research. 


\section{Acknowledgements}

The authors gratefully acknowledge the financial support of the UK EPSRC (grant reference: EP/C008030/1) and the contribution of all the participating researchers from Dundee, Glasgow Caledonian, Loughborough and St. Andrews Universities who make up the SUE-MoT research consortium. In addition, thanks go to those who were involved in the interviews across the four case studies over a number of years.

\section{References}

Addis, M., 2016. Tacit and explicit knowledge in construction management. Construction Management and Economics, 34(7-8), 439-445.

Addis, M., Boyd, D., and Raiden, A., 2016. Special issue: theorising expertise in construction. Construction Management and Economics, 34(7-8), 433-438.

Atkins, R. and Emmanuel, R., 2014. Could refurbishment of “traditional” buildings reduce carbon emissions? Built Environment Project and Asset Management, 4 (3), 221-237.

Bebbington, J., Brown, J., and Frame, B., 2007. Accounting technologies and sustainability assessment models. Ecological Economics, 61(2/3), 224-236.

Bernardi, E., Carlucci, S., Cornaro, C., Bohne, R.A., 2017. An Analysis of the Most Adopted Rating Systems for Assessing the Environmental Impact of Buildings. Sustainability 9(7), 1226-1253.

Bertels, S., Papania, L., Papania, D., 2010. Embedding sustainability in organizational. culture: A Systematic review of the body of knowledge, Network for Business. Sustainability. [online] Available at: <www.nbs.net/knowledge/culture> [Accessed 25th April 2018].

BioRegional Quintain Ltd., 2010. Company objectives, available at: http://www.bioregional-quintain.com/objective.php [accessed 25th April 2018].

Bond, A. and Morrison-Saunders, A., 2011. Re-evaluating sustainability assessment: aligning the vision and the practice. Environmental Impact Assessment Review, 31(1), 1-7.

Bond, A., Morrison-Saunders,A. and Pope, J., 2012. Sustainability assessment: the state of the art. Impact Assessment and Project Appraisal, 30 (1), 53-62. 
Boud, D., 2000. Sustainability Assessment: rethinking assessment for the learning society. Studies in Continuing Education, 22 (2), 151-167.

Brandon, P.S. and Lombardi, P., 2011. Evaluating sustainable development in the built environment. Chichester: John Wiley and Sons.

Chan, P.W., 2016. Expert knowledge in the making: using a processual lens to examine expertise in construction. Construction Management and Economics, 34(7-8), 471-483.

Charmaz, K., 2009. Shifting the grounds: Constructivist grounded theory methods, in Morse, J.M., Stern, P.N., Corbin, J., Bowers, B., Charmaz, K. and Clarke, A.E. (eds.), Developing Grounded Theory: The Second Generation, Walnut Creek: Left Coast Press., 127-154.

Cole, R.J., 2012. Transitioning from green to regenerative design. Building and Information, 40(1), 39-53.

Cole, R. J., 2005. Building environmental assessment methods: Redefining intentions and roles. Building Research and Information, 33(5), 455-467.

Cole, R.J. and Valdebenito, M.J., 2013. The importation of building environmental certification systems: international usages of BREEAM and LEED. Building Research \& Information, 41(6), 662-676.

Cooper, I., 2018. The socialisation of building science: the emblematic journey of R.J. Cole. Building Research and Information, 46:5, 463-468.

Cooper, I., 1999. Which focus for building assessment methods - Environmental performance or sustainability? Building Research \& Information, 27(4/5), 321331.

Daothong, J., and Stubbs, D., 2014. London 2012 legacy: creating a more sustainable future for London and beyond. Proceedings of the Institution of Civil EngineersCivil Engineering, 167(6), 3-12.

Devuyst, D., 1999. Sustainability assessment: application of a methodological framework. Journal of Environment Assessment Policy and Management. 1(4), $459-487$.

Desai, P. and King, P., 2006. One Planet Living - A Guide to Enjoying Life on Our One Planet. Bristol: Alastair Sawday Publishing.

Ding, G. K. C., 2008. Sustainable construction-The role of environmental assessment tools. Journal of Environmental Management, 86(3), 451-464. 
du Plessis, M., 2007. The role of knowledge management in innovation. Journal of Knowledge Management, 11(4), 20-29.

Eccles, R., Ioannou, I. and Serafeim., G. 2014. The impact of corporate sustainability on organizational processes and performance. Management Science, 60 (11), 28352857.

El-Haram, M., Walton, J., Horner, M., Hardcastle, C., Price, A., Bebbington, J., Thomson, C., Atkin-Wright, T., 2007. Development of an Integrated Sustainability Assessment Toolkit. In Horner, M., Hardcastle, C., Price, A., Bebbington, J. Ed., Proceedings of International Conference on Whole Life Urban Sustainability and its Assessment, 27-29 November 2007, Glasgow, http://download.sue-mot.org/Conference-2007/Papers?El-Haram.pdf.

Egbu, C., Hari, S., Renukappa, S., 2005. Knowledge management for sustainable competitiveness in small and medium surveying practices. Structural Survey, 23 (1), 7-21.

Egbu, C.O., Arif, M. and Williams, A., 2011. Knowledge mapping techniques for sustainable urban environment. International Journal of Construction Project Management, 3(3), 269-277.

Eppler. M.J., 2008. Classifying knowledge maps: typologies and application examples. In: Lytras M.D., Russ, M.A., Maier, R. and Naeve, A., ed., Knowledge Management Strategies: a handbook of applied technologies, Hershey: IGI Global, 116-142.

Epstein, D., Jackson, R., Braithwaite, P., 2011. Delivering London 2012: sustainability strategy. Proceedings of the Institution of Civil Engineers- Civil Engineering, 164(5), 27-33.

Freeman, R.E., 2010. Strategic Management: A Stakeholder Approach. Cambridge: Cambridge University Press.

Gioia, D.A., and Pitre, E., 1990. Multiparadigm perspectives on theory building. Academy of Management Review, 15(4), 584-602.

Gibson, R.B., 2012. The Canadian government's new environmental assessment law undoes decades of progress. Impact Assessment and Project Appraisal, 30(3), 259-280.

Girard, J.P. and Girard, J., 2015. Defining knowledge management: Toward an applied compendium, Online Journal of Applied Knowledge Management, 3 (1), 1-20. 
Good Homes Alliance, 2014. GHA Monitoring Programme 2011-2013: technical report- results from phase 2: post occupancy testing of a sample of sustainable new homes. London: Good Homes Alliance.

Graham, P., 2000. Building education for the next industrial revolution: teaching and learning environmental literacy for the building professions, Construction Management and Economics, 18(8), 917-925.

Guo, Z. and Sheffield, J., 2006. A Paradigmatic and Methodological Examination of KM Research: 2000-2004. Proceedings of the 39th Annual Hawaii International Conference on System Sciences, 8, 166.2, doi:10.1109/HICSS.2006.468.

Haddaway, N.R., Kohl, C., Rebelo da Silva, N., Schiemann, A., Stewart, R., Sweet, J.B., Wilhelm, R. 2017. A framework for stakeholder engagement during systemic reviews and maps in environmental management. Environmental Evidence, 6(11), doi: 10.1186/s13750-017-0089-8.

Hakkinen, T. and Belloni, K., 2011. Barriers and drivers for sustainable building. Building Research and Information, 39(3), 239-255.

Hansen, M., Nohria, N., Tierney, T., 1999. What's your strategy for managing knowledge? Harvard Business Review, 77(2), 106-116.

Haroglu, H., 2013.The impact of BREEAM on the design of buildings. Proceedings of ICE: Engineering Sustainability, 166(1), 11-19.

Harty, C., Goodier, C., Soetanto, R., Austin, S., Dainty, A. and Price, A.D.F., 2007. The futures of construction: A critical review of construction future studies. Construction Management and Economics, 25(5), 477-493.

Hassard, J., 1988. Overcoming hermeticism in organisation theory: an alternative to paradigm incommensurability. Human Relations, 41(3), 247-259.

Kaatz, E., Root, D., Bowen, P. \& Hill, R. C., 2006. Advancing key outcomes of sustainability building assessment. Building Research and Information, 34(4), 308-320.

Keen, M., Brown, V. A. and Dyball, R., 2005. Social learning in environmental management: towards a sustainable future, London: Earthscan.

Khalfan, M. A., 2006. Managing sustainability within construction projects, Journal of Environmental Assessment Policy and Management, 8(1), 41-60.

Knox, M., Clevenger, C., Dunbar, B., and Leigh, K., 2014. Impact of Charrettes and Their Characteristics on Achieved LEED Certification. Journal of Architectural Engineering, 20(3), doi:10.1061/(ASCE)AE.1943-5568.0000144. 
Kohler, N. 2018. From the design of green buildings to resilience management of building stocks, Building Research and Information, 46(5), 578-593.

Kolb, D., 1984. Experiential learning: experience as the source of learning and development. New Jersey: Prentice-Hall, Inc.

Leblanc, H., Thomson, C., and Cameron, I., 2015. Developing a sustainability KM strategy for HA planned works. Proceedings of ICE: Management, Procurement and Law, 168(2), 49-65.

Lowe, R., Chiu, L., Oreszczyn, T., 2018. Socio-technical case study method in building evaluation. Building Research and Information, 46(5), 469-484.

Linnenlueke, M.K. and Griffiths, A., 2010. Corporate sustainability and organisational culture, Journal of World Business, 45(4), 357-366.

Lutzkendorf, T. and Lorenz, D., 2011. Capturing sustainability related information for property valuation. Building Research \& Information, 39(3), 26-273.

Mathur, V. N., Price, A. D. F. and Austin, S., 2008. Conceptualising stakeholder engagement in the context of sustainability and its assessment, Construction Management and Economics, 26(6), 601-609.

Metcalf, L. and Benn, S., 2013. Leadership for Sustainability: An Evolution of Leadership Ability, Journal of Business Ethics, 112 (3), 369-384.

Mollaoglu-Korkmaz, S., Swarup, L. \& Riley, D., 2013. Delivering sustainable, highperformance buildings: Influence of project delivery methods on integration and project outcomes. Journal of Management in Engineering, 29(1), 71-78.

Mogendorff, K., 2016. The building or enactment of expertise in context: what the performative turn in the social sciences may add to expertise research in construction management. Construction Management and Economics, 34(7-8), 484-491.

Munro, M. and Jeffrey, P., 2008. A critical review of the theory and application of social learning in participatory natural resource management processes. Journal of Environmental Planning and Management, 51(3), 325-344.

Murray, P.E., and Cotgrave, A.J., 2007. Sustainability literacy: the future paradigm for construction education? Structural Survey, 25(1), 7-23.

Nonaka, I. and Takeuchi, H., 1995. The Knowledge-creating Company. New York: Oxford University Press. 
Oliver, A. and Pearl, D. 2018. Rethinking sustainability frameworks in neighbourhood projects: a process-based approach. Building Research and Information, 46(5), 513-527.

Opoku, A., Cruickshank, H., and Ahmed, V. 2016. Organisational leadership role in the delivery of sustainable construction projects in UK. Built Environment Project and Asset Management, 5(2), 154-169.

Pemsel, S. and Wiewiorab, A., 2014. Project management office a knowledge broker in project-based organisations. International Journal of Project Management, 32(8), 1285-1510

Pope, J., Annandale, D., and Morrison-Saunders, A., 2004. Conceptualising sustainability assessment, Environmental Impact Assessment Review, 24(6), 595-616.

Quinn, L. and Dalton, M. 2009. Leading for sustainability: implementing the tasks of leadership, Corporate Governance: The International Journal of Business in Society, 9(1), 21-38.

Rees, W., 2009. The ecological crisis and self-delusion: implications for the building sector, Building Research and Information, 37(3), 300-311.

RIBA, 2011. Green overlay to the RIBA Plan of Work, in Gething, E. (Ed.), Royal Institute of British Architects, available at: http://www.ribabookshops.com/uploads/9a0204f4-8775-d644-c9d1b2d508c5924b.pdf (accessed 25 April 2018).

Roberston, M., 2017. Sustainability Principles and Practice, Abingdon: Routledge.

Robinson, J. and Cole, R. 2015. Theoretical underpinnings of regenerative sustainability. Building Research and Information, 43(2), 133-143.

Rodela, R., Bregt, A., Ligtenberg, A., Perez-Soba, M., Verweij, P. 2017. The social side of spatial decision support systems: investigating knowledge integration and learning, Environmental Science and Policy, 76(10), 177-184.

Sage, D.J., 2016. Rethinking construction expertise with posthumanism. Construction Management and Economics, 34(7-8), 446-457.

Sanchez, L. E. and Morrison-Saunders, A., 2011. Learning about knowledge management for improving environmental impact assessment in a government agency: The Western Australian experience. Journal of Environmental Management, 92(9), 2290-2271. 
Saunders, M.N.K., Lewis, P., Thornhill, A. and Bristow, A., 2015. Understanding research philosophy and approaches to theory development. In: Saunders, M.N.K., Philip, L. and Thornhill, A. (eds.). Research Methods for Business Students, Harlow: Pearson Education, 122-161.

Schweber, L., 2013. The effect of BREEAM on clients and construction professionals. Building Research \& Information, 41(2), 129-145.

Schweber, L. and Haroglu, H., 2014. Comparing the fit between BREEAM assessment and design processes. Building Research \& Information, 42(3), 300-317

Seinre, E., Kurnitski, J., Voll, H., 2014. Building sustainability objective assessment in Estonian context and a comparative evaluation with LEED and BREEAM. Building and Environment, 82(1), 110-120.

Sheate, W. R. and Partidário, M. R., 2010. Strategic approaches and assessment techniques -Potential for knowledge brokerage towards sustainability, Environmental Impact Assessment Review, 30(4), 278-288.

Silvius, A. and Schipper, R., 2014. Sustainability in project management: A literature review and impact analysis. 4 (1), Westburn Publishers Limited: Helensburgh. Stoughton, A., and Ludema,J., 2012. The driving forces of sustainability, Journal of Organizational Change Management, 25 (4), 501-517.

Stribbe, A. and Luna, H. 2009. An introduction. In: Stribbe, A. (eds.). The handbook of sustainability literacy: skills for a changing world, Cambridge: Green Books.

Suddaby, R., 2006. From the Editors: what grounded theory is not. Academy of Management Journal, 49 (4), 633-642.

Thomson, C., and El-Haram, M. 2014. Potential and implications of sustainability action plans: lessons from the Greater Middlehaven Regeneration Project, Journal of Built Environment Project and Asset Management, 4(1), 108-122.

Thomson, C.S., El-Haram, M.A., and Hardcastle, C. 2009. Managing knowledge of urban sustainability assessment, Proceedings of Institute of Civil Engineering, Engineering Sustainability, 162(1), 35-43.

Thomson, C.S., El- Haram, M.A. and Emmanuel, R. 2010 Managing the knowledge flow during sustainability assessment, Proceedings of Institute of Civil Engineering, Urban Design and Planning, 163(2), 67-78.

van Buuren, A., 2009. Knowledge for governance, governance of knowledge: inclusive knowledge management in collaborative governance processes. International Public Management Journal, 12 (2), 208-235. 
Vestal, W., 2005. Knowledge mapping- the essentials for success, Houston: APQC publications.

Walton, J.S., El-Haram, M., Castillo, N.H., Horner, R.M.W., Price, A.D.F. and Hardcastle, C., 2005. Integrated Assessment of Urban Sustainability, Proceedings of ICE: Engineering Sustainability, 158(2), 57-65.

White, L., and Noble, B., 2013. Strategic environmental assessment for sustainability: a review of a decade of academic research. Environmental Impact Assessment Review, 42(5), 60-66.

Willmott, H., 1993. Breaking the paradigm mentality. Organizational studies, 14, 681721.

Xing, Y., Horner, R. M. W., El Haram, M.A., Bebbington, J., 2009. A framework model for assessing sustainability impacts of urban development. Accounting Forum, 33(3), 209-224. 


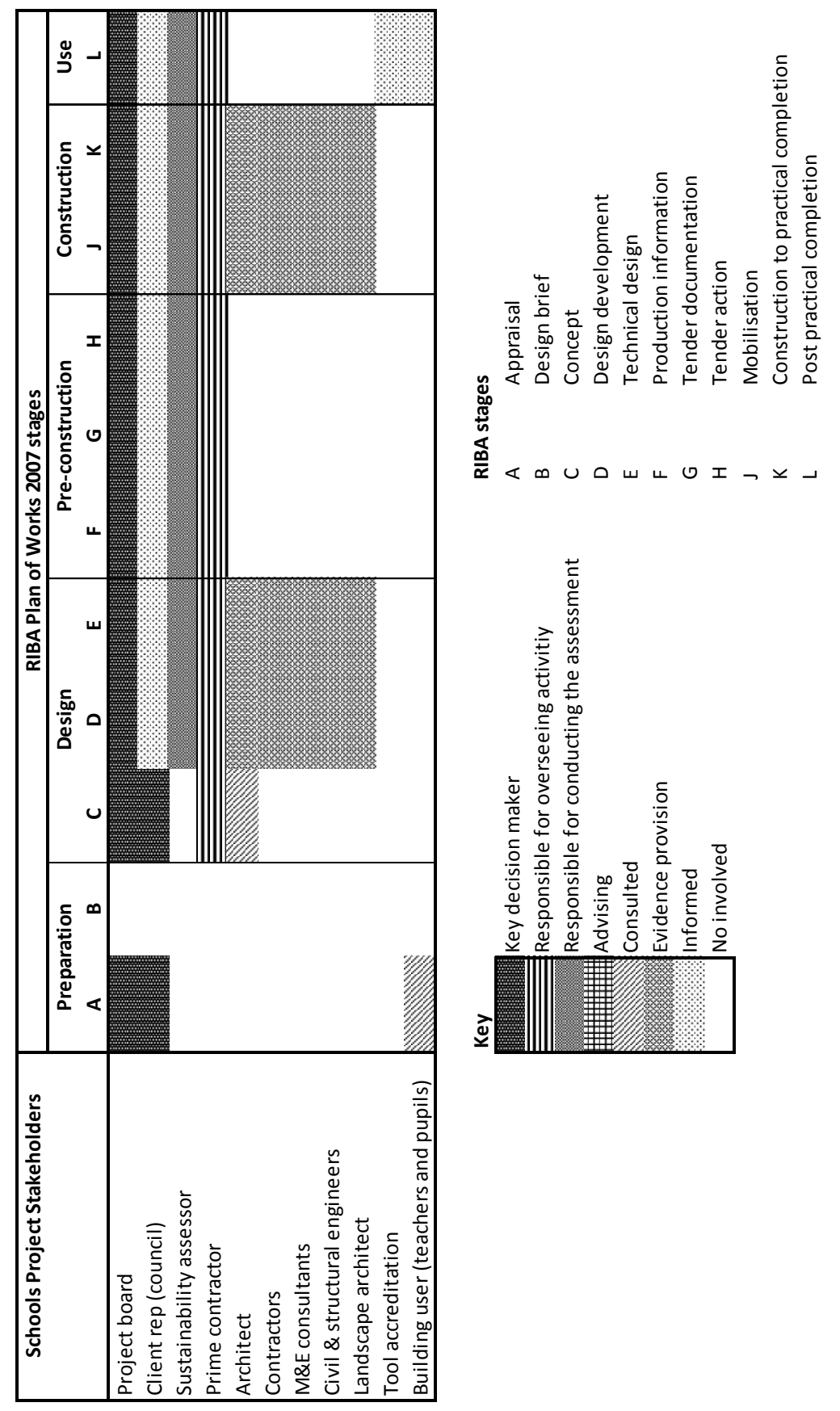

Figure 1: Stakeholder involvement grid for Schools project 


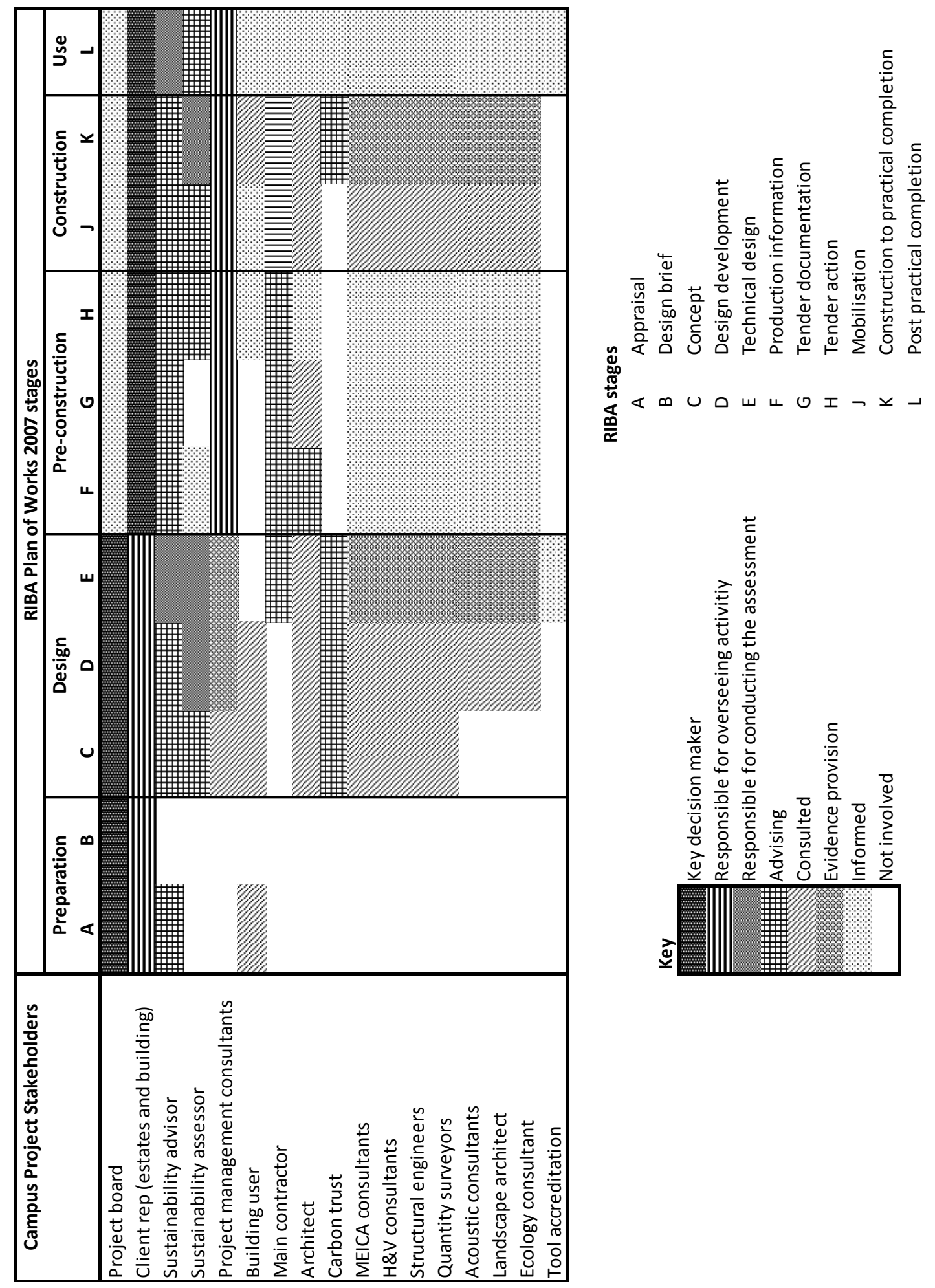

Figure 2: Stakeholder involvement grid for Campus project 


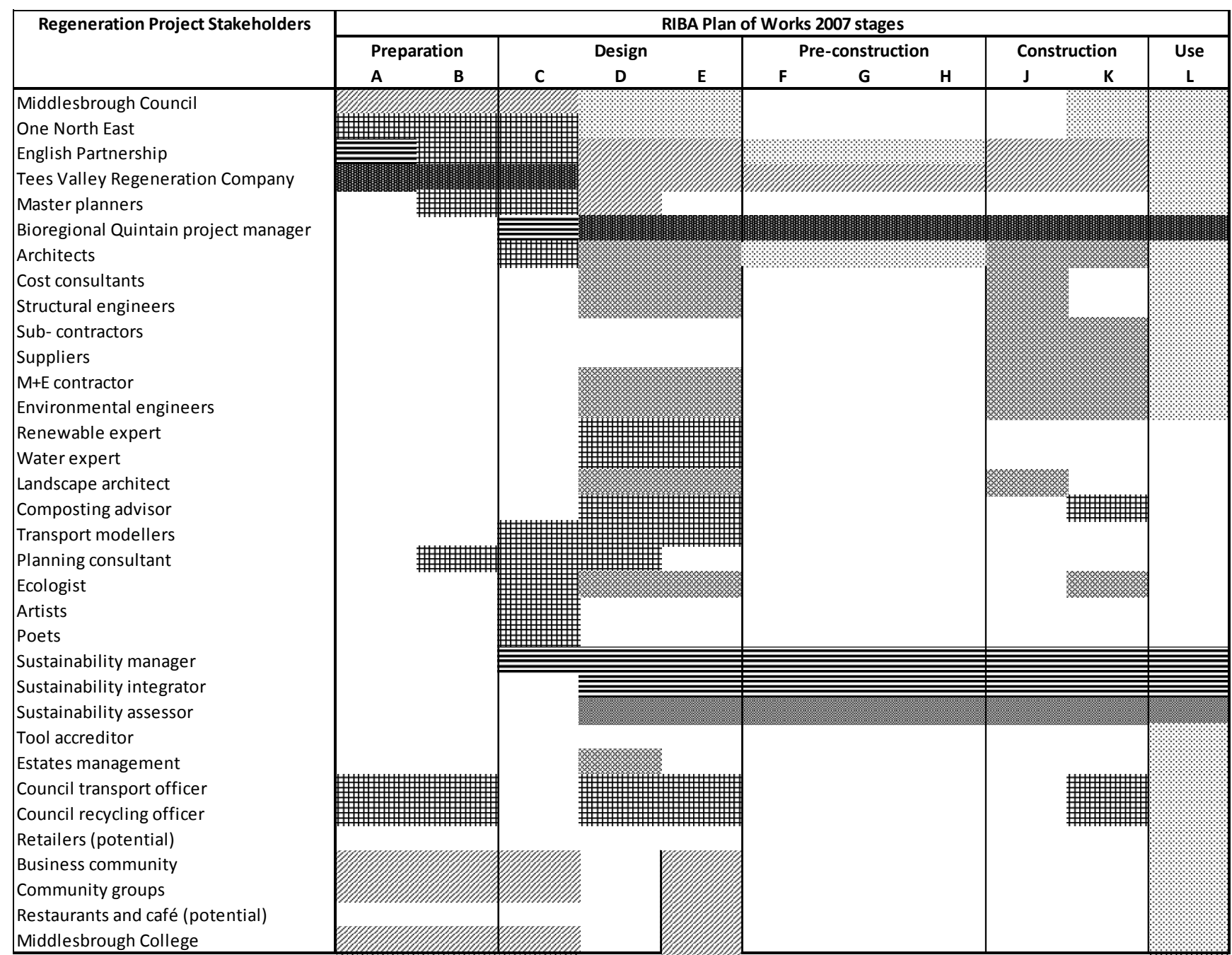

Rey decision maker
Responsible for overseeing activity
Rdvising
Consulted
Evidence provision
Informed
Not involved

$\begin{array}{ll}\text { RIBA stages } \\ \text { A } & \text { Appraisal } \\ \text { B } & \text { Design brief } \\ \text { C } & \text { Concept } \\ \text { D } & \text { Design development } \\ \text { E } & \text { Technical design } \\ \text { F } & \text { Production information } \\ \text { G } & \text { Tender documentation } \\ \text { H } & \text { Tender action } \\ \text { J } & \text { Mobilisation } \\ \text { K } & \text { Construction to practical completion } \\ \text { L } & \text { Post practical completion }\end{array}$

Figure 3: Stakeholder involvement grid for Regeneration project 


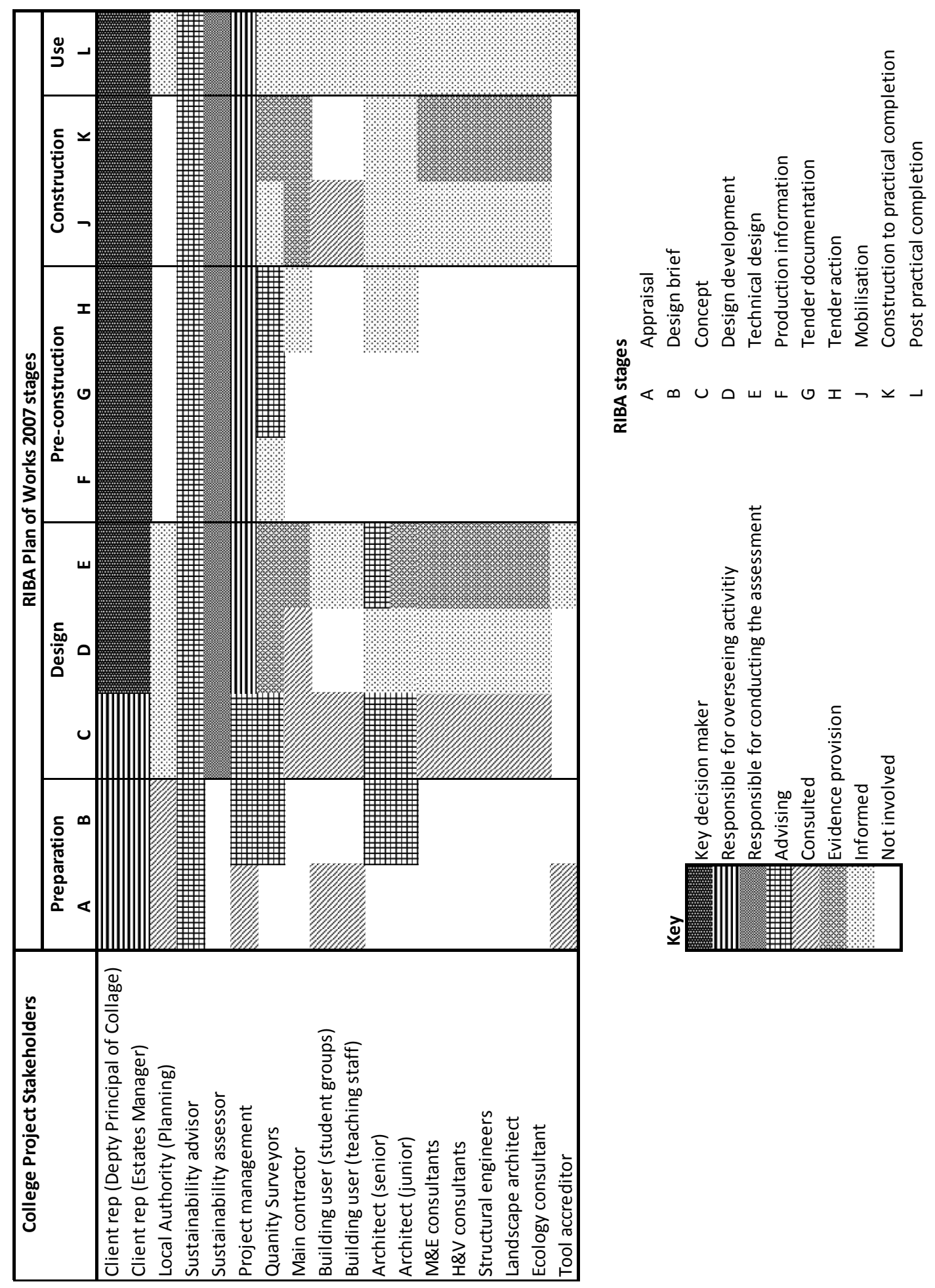

Figure 4: Stakeholder involvement grid for College project 


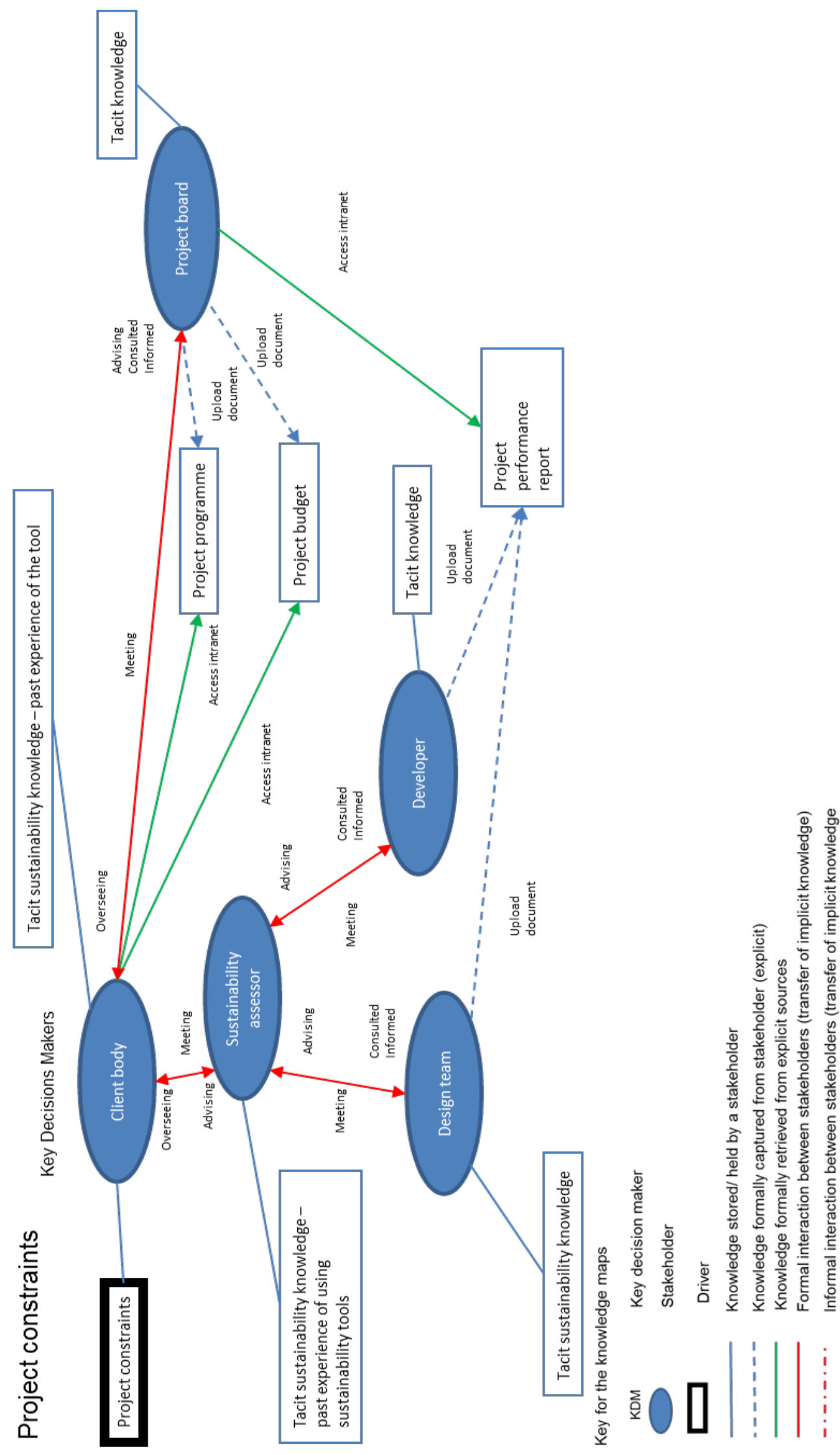

Figure 5: Example knowledge map for the driver of project constraints during assessment phase (Campus project) 


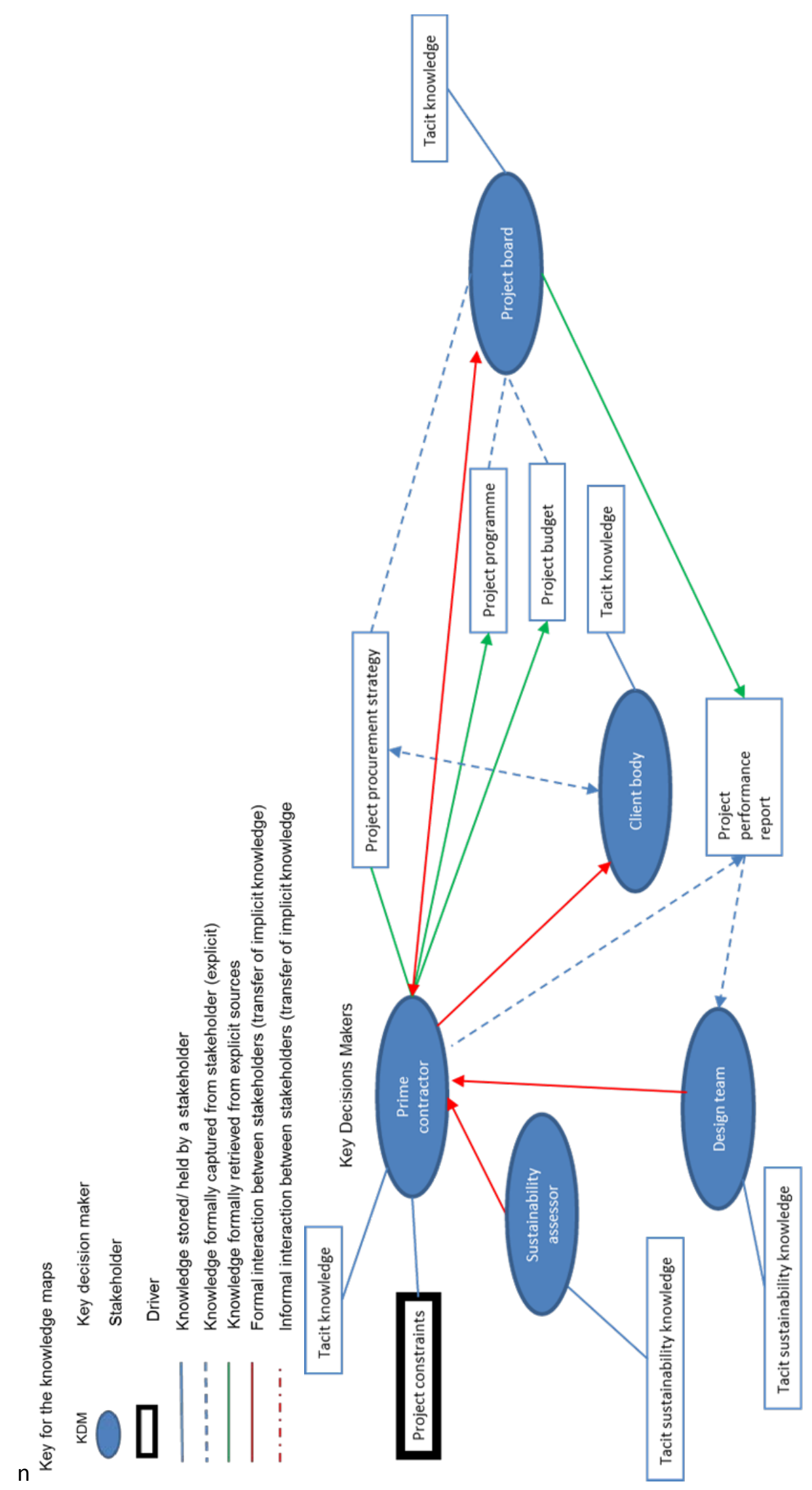

Figure 6: Example knowledge map for the driver of project constraints during assessment phase (Schools project) 
Table 1: Case study alignment with selection criteria

\begin{tabular}{|l|c|c|c|c|}
\hline Criteria & 1 Schools & $\begin{array}{c}\text { 2 University } \\
\text { campus building }\end{array}$ & $\begin{array}{c}\text { 3 Regeneration } \\
\text { project }\end{array}$ & $\begin{array}{c}\text { 4 College } \\
\text { building }\end{array}$ \\
\hline $\begin{array}{l}\text { Priority } \\
\text { towards } \\
\text { sustainability }\end{array}$ & Compliance & Good practice & Aspirational & Good practice \\
\hline $\begin{array}{l}\text { Approach to } \\
\text { assessment }\end{array}$ & Reactive & Proactive & Innovative & Proactive \\
\hline Start date & 2001 & 2006 & 2006 & 2013 \\
\hline $\begin{array}{l}\text { Depth of } \\
\text { sustainability } \\
\text { criteria }\end{array}$ & Basic & Advanced & Deep & Advanced \\
\hline
\end{tabular}


Table 2: Stakeholders interviewed across 4 case studies

\begin{tabular}{|c|c|c|c|c|}
\hline $\begin{array}{l}\text { Case } \\
\text { study }\end{array}$ & 1 Schools & $\begin{array}{l}2 \text { University Campus } \\
\text { building }\end{array}$ & $\begin{array}{l}3 \text { Regeneration } \\
\text { project }\end{array}$ & 4 College building \\
\hline $\begin{array}{l}\text { Project } \\
\text { time line }\end{array}$ & $\begin{array}{l}\text { 2001-2009 (6 } \\
\text { schools) }\end{array}$ & $2006-2010$ & $\begin{array}{l}\text { Phase } 1 \text { 2008- } \\
2012\end{array}$ & 2013-2016 \\
\hline Phase 1 & $\begin{array}{l}\text { Programme } \\
\text { manager (prime } \\
\text { contractor)* }\end{array}$ & $\begin{array}{l}\text { University } \\
\text { environmental } \\
\text { manager (estates } \\
\text { department)* } \\
\text { Project architect }\end{array}$ & $\begin{array}{l}\text { Regeneration } \\
\text { manager } \\
\text { (regeneration } \\
\text { company) } \\
\text { Sustainability } \\
\text { manager } \\
\text { (developer)* }\end{array}$ & $\begin{array}{l}\text { College project } \\
\text { lead (deputy } \\
\text { Principal) }\end{array}$ \\
\hline Phase 2 & $\begin{array}{l}\text { Project architects } \\
\text { (two individuals)* }^{*} \\
\text { BREEAM assessor } \\
\text { Project manager } \\
\text { (contractor) } \\
\text { Client rep (council) } \\
\text { Facilities manager } \\
\text { Site manager } \\
\text { (contractor) }\end{array}$ & $\begin{array}{l}\text { Project architect } \\
\text { (senior) } \\
\text { BREEAM assessor } \\
\text { Main contractor } \\
\text { Site manager } \\
\text { (contactor) } \\
\text { Sustainability advisor }\end{array}$ & $\begin{array}{l}\text { Project architect } \\
\text { Sustainability } \\
\text { assessor } \\
\text { (developer } \\
\text { Sub-contractor } \\
\text { Sustainability } \\
\text { integrator (site } \\
\text { activities)* } \\
\text { Planner from } \\
\text { regeneration } \\
\text { company }\end{array}$ & $\begin{array}{l}\text { Project architect } \\
\text { Quantity Surveyor } \\
\text { Sustainability } \\
\text { advisor }\end{array}$ \\
\hline
\end{tabular}

*Contact retained and follow up interviews conducted until and post completion of project 
Table 3: The top 7 ranked key drivers stimulating knowledge flow for the phases of sustainability assessment

\begin{tabular}{|c|c|c|c|}
\hline $\begin{array}{l}\text { Selecting the } \\
\text { sustainability issues }\end{array}$ & $\begin{array}{l}\text { Selection of } \\
\text { sustainability } \\
\text { assessment tools }\end{array}$ & $\begin{array}{l}\text { Implementation of the } \\
\text { assessment }\end{array}$ & $\begin{array}{l}\text { Consideration of } \\
\text { assessment outputs }\end{array}$ \\
\hline $\begin{array}{l}\text { 1. Regulation } \\
\text { requirements }\end{array}$ & $\begin{array}{l}\text { 1. Funding } \\
\text { requirements }\end{array}$ & $\begin{array}{l}\text { 1. Contractual } \\
\text { requirement }\end{array}$ & $\begin{array}{l}\text { 1. Client requirement/ } \\
\text { expectations }\end{array}$ \\
\hline $\begin{array}{l}\text { 2. Client } \\
\text { requirements }\end{array}$ & $\begin{array}{l}\text { 2. Planning } \\
\text { requirements }\end{array}$ & $\begin{array}{l}\text { 2. Mindset of team } \\
\text { 3. Regulation }\end{array}$ & $\begin{array}{l}\text { 2. Planning } \\
\text { requirements }\end{array}$ \\
\hline $\begin{array}{l}\text { 3. Vision, scope and } \\
\text { desire for }\end{array}$ & $\begin{array}{l}\text { 3. Regulation } \\
\text { requirements }\end{array}$ & $\begin{array}{l}\text { requirements } \\
\text { 4. Ability of team }\end{array}$ & $\begin{array}{l}\text { 3. Regulation } \\
\text { requirements }\end{array}$ \\
\hline $\begin{array}{l}\text { sustainability } \\
\text { 4. Planning context }\end{array}$ & $\begin{array}{l}\text { 4. Client } \\
\text { requirements }\end{array}$ & $\begin{array}{l}\text { 5. Implications on } \\
\text { project }\end{array}$ & $\begin{array}{l}\text { 4. Market advantage, } \\
\text { publicity and }\end{array}$ \\
\hline $\begin{array}{l}\text { 5. Stakeholder values } \\
\text { 6. Project context }\end{array}$ & $\begin{array}{l}\text { 5. Availability of } \\
\text { tools }\end{array}$ & $\begin{array}{l}\text { 6. Management of the } \\
\text { assessment process }\end{array}$ & $\begin{array}{l}\text { reputation } \\
\text { 5. Ability of the }\end{array}$ \\
\hline 7. Ability of the team & $\begin{array}{l}\text { 6. Market advantage } \\
\text { and reputation } \\
\text { 7. Cost of } \\
\text { implementation of } \\
\text { the tool }\end{array}$ & 7. Project constraints & $\begin{array}{l}\text { assessor } \\
\text { 6. Level of funding } \\
\text { requirements } \\
\text { 7. Dissemination to } \\
\text { stakeholders }\end{array}$ \\
\hline
\end{tabular}


Table 4: Knowledge map for expert knowledge during issues selection (Campus project)

\begin{tabular}{|c|c|c|c|c|}
\hline Source & Holder & Pathway & Receptor & Drivers \\
\hline $\begin{array}{l}\text { Expert knowledge } \\
\text { of sustainability } \\
\text { tools }\end{array}$ & $\begin{array}{l}\text { Sustainability } \\
\text { advisor }\end{array}$ & $\begin{array}{l}\text { Employed directly } \\
\text { to advise the } \\
\text { client body }\end{array}$ & Client body & $\begin{array}{l}\text { Client } \\
\text { requirements } \\
\text { Regulation } \\
\text { requirements } \\
\text { Project context }\end{array}$ \\
\hline $\begin{array}{l}\text { Expert knowledge } \\
\text { of delivering } \\
\text { sustainability }\end{array}$ & $\begin{array}{l}\text { Sustainability } \\
\text { advisor } \\
\text { Carbon trust }\end{array}$ & $\begin{array}{l}\text { Employed directly } \\
\text { to advise the } \\
\text { client body }\end{array}$ & Client body & $\begin{array}{l}\text { Project context } \\
\text { Regulation } \\
\text { requirements } \\
\text { Vision, scope and } \\
\text { desire for } \\
\text { sustainability }\end{array}$ \\
\hline $\begin{array}{l}\text { Expert knowledge } \\
\text { of sustainability } \\
\text { concept and } \\
\text { assessment }\end{array}$ & $\begin{array}{l}\text { Sustainability } \\
\text { advisor }\end{array}$ & $\begin{array}{l}\text { Employed directly } \\
\text { to advise the } \\
\text { client body }\end{array}$ & Client body & $\begin{array}{l}\text { Vision, scope and } \\
\text { desire for } \\
\text { sustainability }\end{array}$ \\
\hline
\end{tabular}




\section{IAppendix}

\section{Appendix 1: Process map showing activities related to sustainability assessment across project phases}

\begin{tabular}{|c|c|c|c|c|}
\hline Project Phases & Primary Schools & Campus project & Regeneration project & College project \\
\hline $\begin{array}{l}\text { Phase A: } \\
\text { Appraisal }\end{array}$ & $\begin{array}{ll}\text { - } & \text { Identification of } \\
\text { the tool } \\
\text { (BREEAM) } \\
\text { - } \quad \text { Establish a } \\
\text { sustainability } \\
\text { criteria } \\
\text { - } \quad \text { Set desired } \\
\text { rating (Good) }\end{array}$ & $\begin{array}{ll}- & \text { Appoint a } \\
& \text { sustainability advisor } \\
\text { - } & \text { Identify sustainability } \\
\text { - } & \text { issues } \\
\text { - } & \text { Review of } \\
& \text { Universities own } \\
& \text { sustainability } \\
\text { priorities and } \\
\text { appraisal } \\
\text { - } & \text { Establish a } \\
\text { sustainability criteria } \\
\text { Identification of tool } \\
\text { (BESPOKE BREEAM) } \\
\text { - Set desired rating } \\
\text { (Very Good) }\end{array}$ & $\begin{array}{ll}\text { - } & \text { Identification of } \\
\text { sustainability issues by } \\
\text { key stakeholders } \\
\text { - } \quad \text { Public consultation to } \\
\text { aid process } \\
\text { - } \\
\text { Shape early proposals } \\
\text { with a sustainability } \\
\text { priority } \\
\text { - Consider and align } \\
\text { with Local Authority } \\
\text { sustainability checklist } \\
\text { appraisal }\end{array}$ & $\begin{array}{ll}- & \text { Identification of } \\
\text { - } & \text { the tool (BREEAM) } \\
\text { - } & \text { (Outstanding) } \\
\text { - } & \text { Appoint } \\
\text { sustainability } \\
\text { advisor } \\
\text { - Shape early } \\
\text { proposals with } \\
\text { BREEAM rating at } \\
\text { core }\end{array}$ \\
\hline $\begin{array}{l}\text { Phase B: } \\
\text { Design Brief } \\
\text { and Phase C } \\
\text { Concept }\end{array}$ & $\begin{array}{ll}\text { - } & \text { Appoint a } \\
\text { sustainability } \\
\text { assessor } \\
\text { - } \\
\text { Meeting with } \\
\text { design team }\end{array}$ & $\begin{array}{l}\text { - } \quad \text { Addition of criteria } \\
\text { set by Carbon Trust } \\
\text { for carbon } \\
\text { assessment } \\
\text { - } \quad \text { Appoint assessor } \\
\text { - Strengthening of } \\
\text { criteria on building } \\
\text { performance (energy, } \\
\text { cost and water) and } \\
\text { priorities such as } \\
\text { transport and } \\
\text { biodiversity } \\
\text { Meeting with design } \\
\text { team }\end{array}$ & $\begin{array}{ll}\text { - } & \text { Appointment of a } \\
\text { visionary master } \\
\text { planner } \\
\text { - } & \text { Redefine identified } \\
\text { sustainability issues } \\
\text { - } \quad \text { Development of } \\
\text { master plan } \\
\text { - } \quad \text { Submission for outline } \\
\text { planning } \\
\text { - } \quad \text { Public consultation on } \\
\text { master plan } \\
\text { Local authority, } \\
\text { regional development } \\
\text { sustainability checklist } \\
\text { appraisal } \\
\text { Environmental impact } \\
\text { assessment }\end{array}$ & $\begin{array}{ll}\text { - } & \text { Design teams } \\
\text { invited } \\
\text { - } & \text { Large proportion } \\
\text { of selection } \\
\text { criteria based on } \\
\text { ability to deliver a } \\
\text { sustainable } \\
\text { building (track } \\
\text { record) } \\
\text { Stakeholders } \\
\text { engaged in design } \\
\text { process } \\
\text { BREEAM assessor } \\
\text { appointed } \\
\text { Sustainability } \\
\text { advisor sets } \\
\text { requirements for } \\
\text { design criteria } \\
\end{array}$ \\
\hline $\begin{array}{l}\text { Phase D: } \\
\text { Design } \\
\text { Development }\end{array}$ & $\begin{array}{l}\text { - } \text { Pre-assessment } \\
\text { report }\end{array}$ & $\begin{array}{ll}\text { - } & \text { Design team provide } \\
\text { - } & \text { evidence } \\
\text { - } & \text { sustainassessment } \\
\text { Identification of } \\
\text { design and cost } \\
\text { implications of } \\
\text { improving } \\
\text { sustainability } \\
\text { performance } \\
\text { Decision to increase } \\
\text { BREEAM target rating } \\
\text { to Excellent }\end{array}$ & 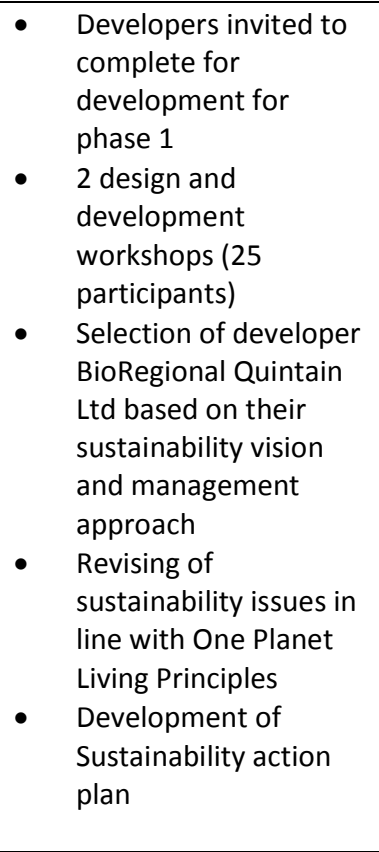 & $\begin{array}{ll}\text { - } & \text { Developer } \\
\text { selection process } \\
\text { initiated } \\
\text { Developers } \\
\text { interviewed and } \\
\text { those with } \\
\text { experience of } \\
\text { delivering high } \\
\text { rated BREEAM } \\
\text { building selected } \\
\text { Contracts signed } \\
\text { with stated goal of } \\
\text { achieving } \\
\text { Outstanding } \\
\text { building } \\
\text { Design and } \\
\text { development } \\
\text { team work } \\
\text { together to } \\
\text { deliver design } \\
\text { Pre-assessment } \\
\text { sustainability }\end{array}$ \\
\hline
\end{tabular}




\begin{tabular}{|c|c|c|c|c|}
\hline & & & & report \\
\hline $\begin{array}{l}\text { Phase E: } \\
\text { Technical } \\
\text { Design }\end{array}$ & $\begin{array}{ll}- & \text { Design team } \\
\text { provide evidence } \\
\text { - } \\
\text { Collation of } \\
\text { evidence for } \\
\text { design stage } \\
\text { BREEAM } \\
\text { assessment } \\
\text { Compile report } \\
\text { for the team } \\
\text { Share report } \\
\text { with team } \\
\text { Preparation of } \\
\text { final BRE report }\end{array}$ & $\begin{array}{ll}\text { - } & \text { Focus on functionality } \\
\text { of building for users } \\
\text { - } & \text { Pre-assessment } \\
\text { report for BREEAM } & \text { and wider criteria } \\
\text { - } & \text { Carbon assessment } \\
\text { with Carbon Trust } \\
\text { - Design modification } \\
\text { to maximise rating } \\
\text { score }\end{array}$ & $\begin{array}{ll}\text { - } & \text { Design developed to } \\
\text { reflect Code for } \\
\text { Sustainable Homes } \\
\text { (Code } 5 / 6 \text { standard) } \\
\text { - } \quad \text { Pre-assessment report } \\
\text { for Ecohomes } \\
\text { - Assessment of } \\
\text { potential for } \\
\text { renewables } \\
\text { technologies }\end{array}$ & $\begin{array}{ll}\text { - } & \text { Focus on } \\
\text { functionality of } \\
\text { building for users } \\
\text { and aligning } \\
\text { BREEAM criteria } \\
\text { Decisions taken } \\
\text { regarding } \\
\text { inclusion of } \\
\text { energy solutions } \\
\text { and materials } \\
\text { Energy } \\
\text { assessments of } \\
\text { the design with } \\
\text { view to BMS }\end{array}$ \\
\hline $\begin{array}{l}\text { Phase F-H: } \\
\text { Production } \\
\text { information, } \\
\text { Tender } \\
\text { Documentation } \\
\text { and Tender } \\
\text { Action }\end{array}$ & $\begin{array}{l}\text { BREEAM criteria } \\
\text { reflected in the } \\
\text { procurement of } \\
\text { materials. }\end{array}$ & $\begin{array}{l}\text { Embedding } \\
\text { sustainability criteria } \\
\text { into the procurement } \\
\text { for materials, } \\
\text { selection of } \\
\text { contractors } \\
\text { Selection of main } \\
\text { contractor with } \\
\text { experience in } \\
\text { sustainable } \\
\text { construction } \\
\text { Emphasis on whole } \\
\text { life costing principles } \\
\text { to ensure operational } \\
\text { costs are minimised }\end{array}$ & 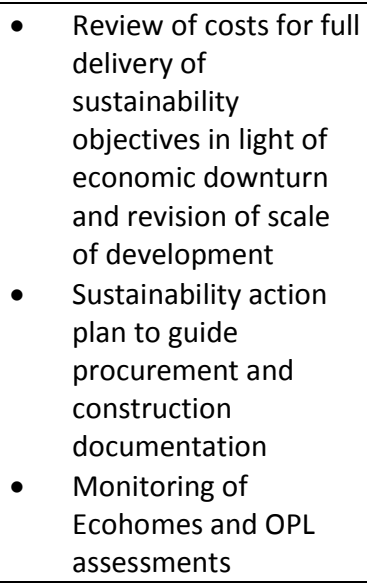 & $\begin{array}{l}\text { Embedding } \\
\text { sustainability } \\
\text { criteria into the } \\
\text { procurement for } \\
\text { materials, } \\
\text { selection of } \\
\text { contractors } \\
\text { Emphasis on } \\
\text { whole life costing } \\
\text { principles to } \\
\text { ensure } \\
\text { operational costs } \\
\text { are minimised } \\
\text { Requirements for } \\
\text { BMS established }\end{array}$ \\
\hline $\begin{array}{l}\text { Phase J: } \\
\text { Mobilisation } \\
\text { and Phase K: } \\
\text { Completion }\end{array}$ & $\begin{array}{l}\text { Monitoring to } \\
\text { ensure that } \\
\text { BREEAM criteria } \\
\text { is reflected in the } \\
\text { construction plan }\end{array}$ & $\begin{array}{ll}\text { - } & \text { Construction site } \\
\text { impact assessment } \\
\text { (health and safety, } \\
\text { noise and transport) } \\
\text { - Emphasis on } \\
\text { construction quality } \\
\text { - } \text { Monitoring Local } \\
\text { Authority check list } \\
\text { Monitoring and } \\
\text { auditing sustainability } \\
\text { performance during } \\
\text { construction } \\
\text { Assessment of } \\
\text { materials supplier } \\
\text { data sheets } \\
\text { Emphasis on } \\
\text { maximising potential } \\
\text { where possible } \\
\text { sustainability criteria } \\
\text { Post construction } \\
\text { review }\end{array}$ & 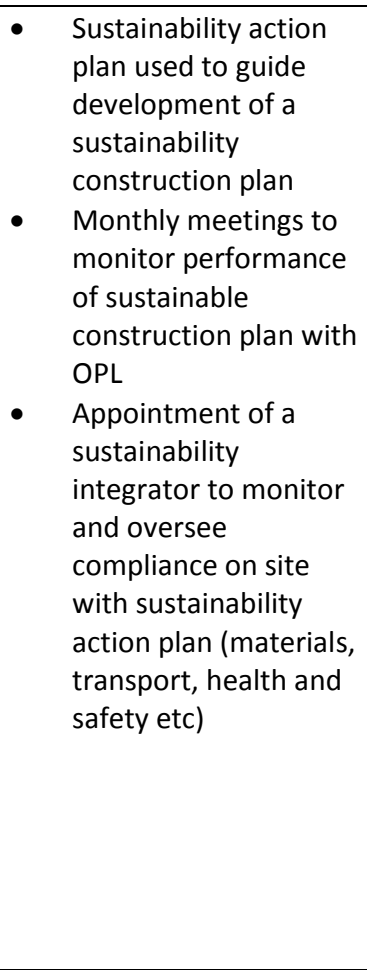 & 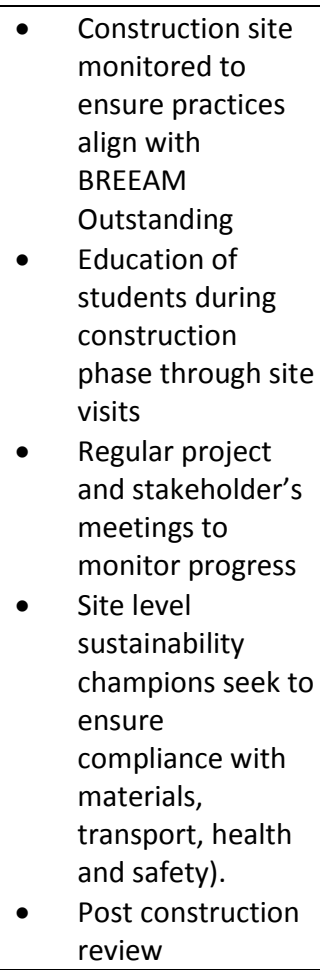 \\
\hline $\begin{array}{l}\text { Phase L: Post } \\
\text { Practical } \\
\text { Completion } \\
\text { (Use) }\end{array}$ & $\begin{array}{ll}\text { - } & \text { Post-occupancy } \\
\text { evaluation } \\
\text { review } \\
\text { Due to timeline, } \\
\text { no need for a } \\
\text { formal BREEAM } \\
\text { assessment post }\end{array}$ & $\begin{array}{ll}\text { - } & \text { Post occupancy } \\
\text { evaluation } \\
\text { - } \quad \text { Collation of evidence } \\
\text { for BREEAM } \\
\text { assessment } \\
\text { - Collation of evidence } \\
\text { for additional }\end{array}$ & $\begin{array}{ll}\text { - } & \text { Sustainability action } \\
\text { plan used to guide } \\
\text { estates management } \\
\text { - Sustainable } \\
\text { monitoring of actual } \\
\text { performance and } \\
\text { review meetings }\end{array}$ & $\begin{array}{ll}-\quad & \text { Post occupancy } \\
\text { evaluation } \\
\text { - } \quad \text { Collation of } \\
\text { evidence for } \\
\text { BREEAM } \\
\text { assessment } \\
\text { - } \text { Dissemination of }\end{array}$ \\
\hline
\end{tabular}




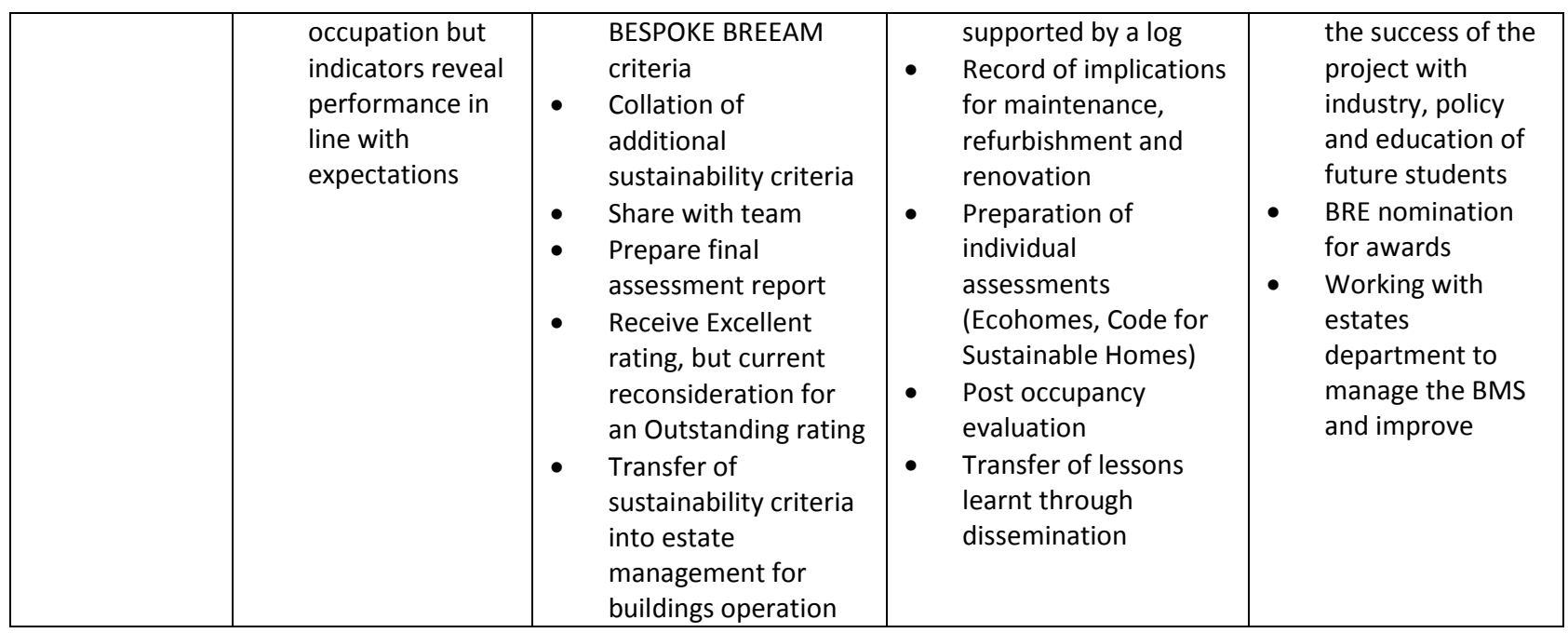


Appendix 2: Project stakeholder involvement grid across project phase with stakeholder assessment (Regeneration project)
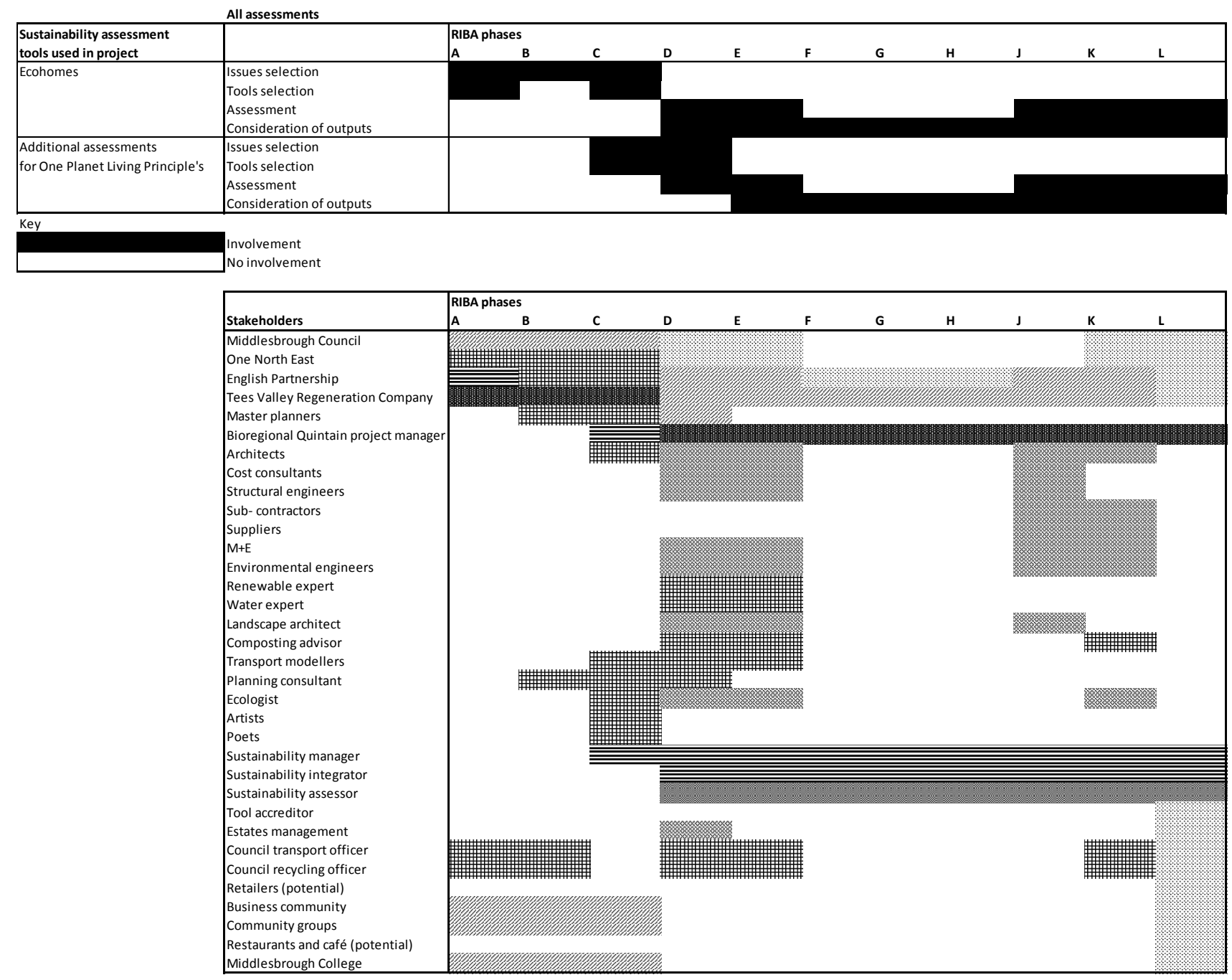

Key decision maker
Responsible for overseeing activity
Responsible for conducting the assessment
Eonsulted
Evidence provision
Informed
Not involved

RIBA phases

A Appraisal

B Design brief

Concept

Design development

Technical design

Production information

Tender documentation

Tender action

Mobilisation

Construction to practical completion

Post practical completion 
Appendix 3: Classification of knowledge sources for Campus project (issues selection phase)

\begin{tabular}{|c|c|c|}
\hline Type of knowledge & $\begin{array}{l}\text { Classification of knowledge } \\
\text { sources }\end{array}$ & Source \\
\hline \multirow[t]{3}{*}{ Explicit knowledge } & $\begin{array}{l}\text { Planning and regulation } \\
\text { documents }\end{array}$ & $\begin{array}{l}\text { - Council's strategic plan } \\
\text { - } \quad \text { Council's planning regulations' } \\
\text { - } \quad \text { Council's sustainability strategy } \\
\text { - Environmental regulations (SEPA) } \\
\text { - } \quad \text { Building regulations and standards }\end{array}$ \\
\hline & Client based documents & $\begin{array}{l}\text { - Universities strategic plan } \\
\text { - Universities sustainability statement and } \\
\text { strategy } \\
\text { - Universities master plan }\end{array}$ \\
\hline & Project based documents & $\begin{array}{l}\text { - } \quad \text { Project programme } \\
\text { - } \quad \text { Project budget } \\
\text { - } \quad \text { Facilities management requirements } \\
\text { and demands }\end{array}$ \\
\hline \multirow[t]{4}{*}{ Implicit knowledge } & $\begin{array}{l}\text { Stakeholders values and } \\
\text { requirements }\end{array}$ & $\begin{array}{l}\text { - } \quad \text { Preferences of staff and student bodies } \\
\text { - } \quad \text { Building users requirements } \\
\text { - Outcome of engagement with local } \\
\text { community, university, building users, } \\
\text { local authority } \\
\text { - Mindset of the team }\end{array}$ \\
\hline & Expert knowledge & $\begin{array}{l}\text { - Expert knowledge of sustainability tools } \\
\text { - Expert knowledge of delivering } \\
\text { sustainability } \\
\text { - } \quad \text { Expert knowledge of sustainability } \\
\text { concept assessment }\end{array}$ \\
\hline & $\begin{array}{l}\text { Tacit sustainability related } \\
\text { knowledge }\end{array}$ & $\begin{array}{l}\text { - Past experience of sustainability } \\
\text { - } \quad \text { Past experience of sustainability tools } \\
\text { - } \quad \text { Acquired knowledge relating to } \\
\text { sustainability and its assessment gained } \\
\text { through professional practice regarding } \\
\text { planning, design, construction, facilities } \\
\text { management and demolition }\end{array}$ \\
\hline & Tacit knowledge & $\begin{array}{l}\text { Acquired knowledge gained through } \\
\text { professional practice regarding } \\
\text { planning, design, construction, facilities } \\
\text { management and demolition }\end{array}$ \\
\hline
\end{tabular}

